\title{
Projected late 21st century changes to the regional impacts of the EI Niño-Southern Oscillation
}

\author{
S. J. Perry ${ }^{1,2,3}$ - S. McGregor ${ }^{2,4} \cdot$ A. Sen Gupta ${ }^{1,4} \cdot$ M. H. England ${ }^{1,4} \cdot$ N. Maher ${ }^{5}$
}

Received: 16 May 2019 / Accepted: 1 October 2019 / Published online: 12 October 2019

\begin{abstract}
As the dominant driver of interannual climate variability globally, any changes in the remote impacts of the El Niño-Southern Oscillation (ENSO) due to climate change are of considerable importance. Here we assess whether climate models from Phase 5 of the Coupled Model Intercomparison Project (CMIP5) project robust changes in ENSO's regional temperature and precipitation teleconnections in the late 21st century, comparing the historical simulations (between 1950 and 1999) and high-emission future simulations (between 2040 and 2089). In order to quantify the importance of internal variability in these projected changes, we examine an ensemble of coupled model simulations from the Max-Planck-Institute Grand Ensemble (MPI-GE). Except for a few regions, the changes in ENSO's temperature and precipitation teleconnections for most regions are not significant across the majority of models. Exceptions include consistent projected changes to temperature teleconnections over equatorial South America and East Africa, which are robust during La Niña events. Despite this, by assessing all regions together, a significant amplification of the temperature teleconnections is identified for La Niña events. Additionally, we find an overall projected weakening relative to the historical precipitation teleconnection when analysis is limited to regions that correctly reproduce the observed precipitation teleconnections. It remains unclear to what extent a change in regional ENSO teleconnections will be apparent, as it is clear that the changes in ENSO's teleconnections are relatively small compared to the regional variability during the historical period.
\end{abstract}

Keywords El Niño-Southern Oscillation · Teleconnections · Future projections

\section{Introduction}

Electronic supplementary material The online version of this article (https://doi.org/10.1007/s00382-019-05006-6) contains supplementary material, which is available to authorized users.

S. J. Perry

s.perry@student.unsw.edu.au

1 Climate Change Research Centre, University of New South Wales, Sydney, NSW, Australia

2 School of Earth, Atmosphere, and Environment, Monash University, Melbourne, VIC, Australia

3 Australian Research Council Centre of Excellence for Climate System Science, University of New South Wales, Sydney, NSW, Australia

4 Australian Research Council Centre of Excellence for Climate Extremes, University of New South Wales, Sydney, NSW, Australia

5 Max Planck Institute for Meteorology, Hamburg, Germany
On interannual timescales, the world's primary driver of internal climate variability originates from the tropical Pacific Ocean: the El Niño-Southern Oscillation (ENSO). El Niño (warm phase) and La Niña (cold phase) events typically occur every 2-7 years, and contribute to substantial interannual temperature and precipitation variability across much of the world (e.g. Diaz et al. 2001; McPhaden et al. 2006; Yeh et al. 2018). ENSO's impacts over land areas are the result of large-scale changes in atmospheric circulation. These changes arise in part from a reorganisation of the zonal Pacific Walker circulation, driven by anomalous diabatic heating of the tropical atmosphere, as ENSO-driven sea surface temperature anomalies (SSTAs) lead to a reorganisation of tropical convection patterns (e.g. Choi et al. 2015; Chiang and Sobel 2002; Su and Neelin 2003; Klein et al. 1999; Gill 1980). In addition, ENSO-driven changes in deep convection also modify divergence in the upper atmosphere, exciting Rossby wave trains that propagate into the 
extratropics and subsequently alter the mid-latitude storm tracks and associated weather variability (e.g. Hoskins and Karoly 1981; Trenberth et al. 1998).

Anthropogenic climate change may alter ENSO's teleconnections in two ways: (1) through changes in the dynamics and or characteristics of ENSO; for example, due to changes in the frequency, amplitude or spatial pattern of SSTAs associated with ENSO; and (2) through changes in the atmospheric response to ENSO SSTAs, which can arise due to changes in the mean state of the Pacific climate system (Yeh et al. 2018; Cai et al. 2015a; Collins et al. 2010). Climate models show limited agreement in projections of future changes to the intensity and frequency of ENSO SSTAs (e.g. Collins et al. 2010; Chen et al. 2017; Maher et al. 2018). This is due in part to inter-model differences in the atmospheric and oceanic feedbacks which govern ENSO in climate models (e.g. Vijayeta and Dommenget 2017; Watanabe et al. 2012; Vecchi and Wittenberg 2010; Cai et al. 2015a). On the other hand, robust (i.e. with strong inter-model agreement) mean state changes in the Pacific climate system are projected in coupled climate models, which act to alter the atmospheric response to ENSO. For example, Power et al. (2013) showed that ENSO-driven precipitation changes in the tropical Pacific are expected to increase nonlinearly in a warmer climate. The warmer background SSTs and increased atmospheric temperature and humidity give rise to this enhanced ENSO rainfall response (e.g. Huang and Xie 2015; Huang 2016), which represents an increase in ENSO extremes (Cai et al. 2014, 2015b).

The extent to which this amplification in ENSO-driven precipitation anomalies in the tropics will also amplify teleconnections outside of the tropical Pacific is of high societal relevance, but uncertainties remain (e.g. Seager et al. 2012; Stevenson et al. 2012). Using models from Phase 5 of the Coupled Model Intercomparison Project (CMIP5), Bonfils et al. (2015) identify projected changes in the global precipitation teleconnections, showing that CMIP5 models simulate intensified precipitation anomalies during ENSO events in most locations. This is especially evident in the models that project an increase in ENSO amplitude (Bonfils et al. 2015). Furthermore, Perry et al. (2017) showed that the majority of CMIP5 models project an increase in the areal extent of significant ENSO temperature and precipitation teleconnections over global land areas. However, the change in magnitude at the grid-point scale was not clear, suggesting that the models do not project a uniform amplification of the historical teleconnections over land (Perry et al. 2017).

Further studies have focused on projected changes in ENSO's impacts for specific regions. Much attention has been given to the ENSO teleconnection to North America, which is expected to shift eastward (e.g. Meehl and Teng 2007; Kug et al. 2010; Herceg Bulić et al. 2012) and strengthen, expanding the associated precipitation and temperature anomalies relative to the historical period (Zhou et al. 2014; Oh et al. 2014). For other regions, the changes in ENSO's impacts are less clear. For example, Hu et al. (2014) show that the lagged El Niño teleconnection to East Asia is projected to strengthen, although not all CMIP5 models capture this teleconnection in the historical period (e.g. Hu et al. 2014; Kim et al. 2016). Steinhoff et al. (2014) show that there is significant spread in the CMIP5 ensemble with regard to the projected changes in the ENSO precipitation teleconnections over equatorial South America, despite models showing agreement on changes in the mean precipitation, consistent with earlier studies (e.g. Grimm 2011). Bonfils et al. (2015) examine changes in the precipitation teleconnections for five land regions; southwest United States, Mexico, northern Brazil, west Africa and northern Australia. They show that on average CMIP5 models project an amplification of the ENSO impacts on precipitation for all regions except Mexico, which was shown to weaken. They also note that the uncertainty in these changes is high, as the signal lies within the range of historical variability (Bonfils et al. 2015; see their Figure 7).

In a recent study, Power and Delage (2018; hereafter referred to as PD18) identify projected changes in ENSO's regional temperature and precipitation teleconnections in twenty-one regions defined by the Intergovernmental Panel on Climate Change (IPCC), covering most of the global land area. They show that many regions demonstrate amplified future ENSO precipitation teleconnections during austral summer and winter. Similarly, the temperature teleconnections during austral winter are also projected to strengthen in the future, compared to the 20th century mean. However, as the PD18 analysis focuses on the CMIP5 ensemble mean, it remains unclear to what extent the individual CMIP5 models agree on these changes. It also remains unclear whether there are comparable changes in ENSO's impacts on temperature variability during austral summer.

An important limitation in identifying robust changes in ENSO's teleconnections is the influence of internal variability (e.g. Brands 2017; Sterl et al. 2007; Yeh et al. 2018). Although ENSO is the dominant mode of climate variability, it only accounts for a small portion of the total variability for many regions, particularly those outside of the tropics (e.g. Diaz et al. 2001). Non-ENSO related variability will confound the spatial pattern and magnitude of ENSO teleconnections in the absence of any changes in ENSO characteristics (e.g. Van Rensch et al. 2015). In observations and models, this is further complicated by the fact that ENSO events have substantial inter-event diversity, both in the amplitude and spatial patterns of SSTA, which alters the remote teleconnections (e.g. Ashok et al. 2007; Timmermann et al. 2018; Taschetto et al. 2014). In model studies, large ensembles of simulations enable the separation of forced ENSO signals and internal variability (e.g. 
Fasullo et al. 2018; Deser et al. 2017). For example, Fasullo et al. (2018) show that the National Centre for Atmospheric Research (NCAR) Community Earth System Model (CESM) large ensemble, consisting of 40 perturbed initial condition simulations, projects a robust strengthening of ENSO's temperature teleconnections over North America, Australia and South America with future warming. Similar changes are also found in a second large ensemble of 30 Geophysical Fluid Dynamics Laboratory (GDFL) Earth System Model (GFDL-ESM2M) simulations (Rodgers et al. 2015), although this model shows a weakening of the temperature teleconnection projected for the Amazon region, highlighting issues of model-dependent changes (Fasullo et al. 2018).

Here, as in PD18, we focus on regional average ENSO teleconnections over land in order to improve the signal to noise ratio of projected changes in the impacts of ENSO. A composite analysis is used to identify ENSO teleconnections in the historical and projected future high-emission (RCP8.5 scenario) simulations. This allows us to identify any asymmetries in the teleconnection changes between El Niño and La Niña events. In addition, unlike previous studies, we will undertake a global analysis, and maintain a strong focus on temperature teleconnections. We will also present analyses of individual ensemble members to provide a more thorough assessment of model agreement and uncertainty. Furthermore, we utilise the recent 100-member ensemble of simulations from the Max-Planck-Institute Grand Ensemble (MPI-GE; Bittner et al. 2016; Stevens 2015) to quantify the effects of internal variability, and to aid in the identification of robust projected changes in the teleconnections for this model and the CMIP5 ensemble.

\section{Models and data}

\subsection{CMIP5 models}

Monthly surface temperature and precipitation output are analysed for an ensemble of 40 CMIP5 models (Taylor et al. 2012), listed in Fig. 1. We compare two fifty year periods, 1950-1999 in the historical simulations, and 2040-2089 in the high-emission RCP8.5 simulations, hereafter referred to as the historical and future periods, respectively. Although some models have archived multiple ensemble members, for consistency across the ensemble we analyse output for 1 ensemble member (r1i1p1) for each model. Model output is first interpolated to a $1.5^{\circ}$ latitude by $1.5^{\circ}$ longitude grid. A high-pass spectral filter is applied to remove variability with a period greater than 13 years, including the climatological mean, the global warming signal, and multidecadal variability. We discard the first and last 10 years to minimise edge-effects introduced by the spectral filter. The fifty-year monthly mean climatology for each period is subtracted

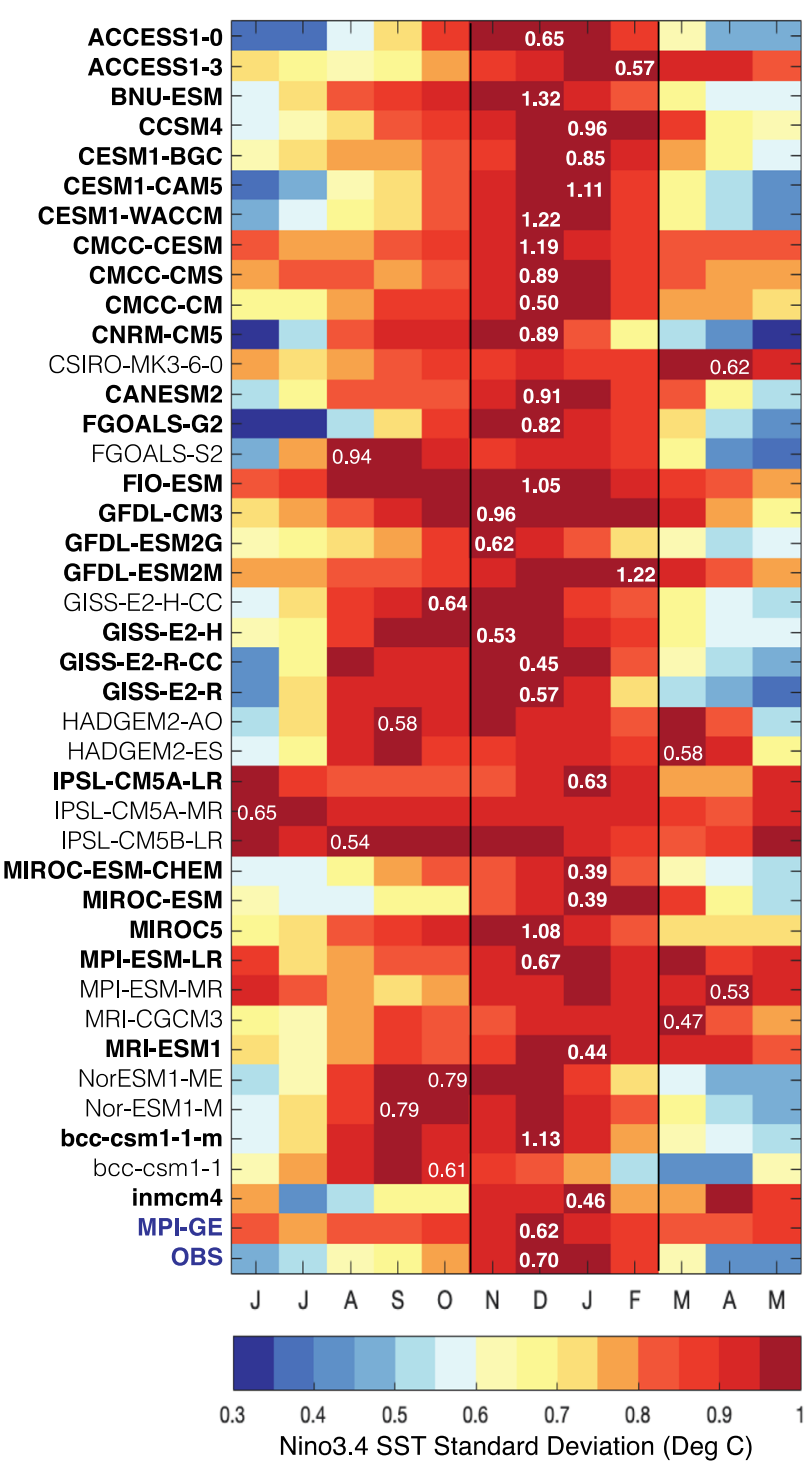

Fig. 1 Monthly standard deviation of the Niño 3.4 region SST during the historical period (1950-1999) for 40 CMIP5 models and NCEP/ NCAR reanalysis surface temperature. The monthly standard deviation is normalised by the maximum standard deviation for each model for comparison. The Niño 3.4 region SST standard deviation during DJF is shown in white, indicating the maximum monthly standard deviation. Models indicated in bold are selected for the remaining analysis

to remove the seasonal cycle. The remaining analysis is focused on austral summer December-January-February (DJF) seasonal anomalies, when ENSO variability peaks in the tropical Pacific. This method is consistent with the approach taken by Power et al. (2013). Additionally, we assess internal variability in the CMIP5 models using the pre-industrial control simulations. We focus on models with simulations at least 500-years long, available for all but two models (GISS-E2-R-CC and MRI-ESM1) analysed here (Fig. 1), and apply the same data processing described 
above. We analyse 50-year periods from each simulation, and although some models have archived pre-industrial control simulations longer than 500-years, we use the same number of periods for each model.

\subsection{Max-Planck-Institute grand ensemble}

In addition to the CMIP5 ensemble, we analyse monthly surface temperature and precipitation from the Max-PlanckInstitute grand ensemble (MPI-GE; Maher et al. 2019; see also Bittner et al. 2016; Stevens 2015). The MPI-GE is a perturbed initial condition experiment, consisting of 100 simulations of the MPI-ESM model in the low-resolution configuration (MPI-ESM1.1). The MPI-GE was chosen because of the large ensemble size, with 100 ensemble members available for both the historical and RCP8.5 future scenario simulations. The large ensemble of simulations allows us to effectively isolate statistically significant ENSO teleconnections, while also enabling us to estimate the influence of internal variability and anthropogenically induced changes (albeit for a single model). For a full description of the MPIGE model see Maher et al. (2019). For comparison with the CMIP5 ensemble we apply the same data processing as described above.

\subsection{Observational data}

Surface temperature from the National Centers for Environmental Prediction (NCEP)/NCAR reanalysis (Kalnay et al. 1996) dataset are analysed for the period 1948-2010. Global observations of precipitation from the CPC Merged Analysis of Precipitation (CMAP) data set are analysed between 1979 and 2015 (Xie and Arkin 1997). Observational data are regridded, high-pass filtered and DJF means are calculated, following the same procedure outlined above. The first and last 5 years of the temperature observations are discarded to minimise edge effects introduced by the spectral filter, thus a comparable fifty-year historical period is analysed for temperature between 1953 and 2002. To conserve the length of the precipitation observations, the first and last 3 years are discarded, thus global precipitation is analysed for a shorter period between 1982 and 2012.

\subsection{Model validation}

We first assess the seasonality of the simulated ENSO variability as a measure of model fidelity. ENSO is synchronised to the seasonal cycle, developing in austral spring and maturing in austral summer (Horel and Wallace 1981). ENSO's seasonality has implications for remote teleconnections that depend on interactions with climatological circulation patterns, which have inherent seasonality (e.g. Diaz et al. 2001). Thus, models that do not correctly simulate the seasonality of ENSO are unlikely to adequately reproduce the remote teleconnections (Joseph and Nigam 2006). Following previous studies (e.g. Bellenger et al. 2014; Taschetto et al. 2014; Latif et al. 2001) we assess the simulated seasonality of ENSO by comparing the monthly standard deviation of SST anomalies in the Niño 3.4 region $\left(190-240^{\circ} \mathrm{E}\right.$, $5^{\circ} \mathrm{S}-5^{\circ} \mathrm{N}$ ) during the historical period with the observations (Fig. 1). Additionally, for reference we show how accurately the model's simulate the amplitude of ENSO by comparing the standard deviation of Niño3.4 region SST anomalies during DJF for the historical period (white text, Fig. 1). Figure 1 shows that 28 out of the 40 CMIP5 models analysed show maximum SST variability in the Niño 3.4 region between November and February (models shown in bold; white text indicates month of maximum SST variability). Note that the MPI-GE shows maximum variability in this period. This is comparable to the observations, which show maximum variability in December (last row Fig. 1; see also Bellenger et al. 2014; Taschetto et al. 2014). In other models, SST variability peaks at the wrong time, for example, CSIROMK3-6-0 reaches a maximum in March-April, while FGOALS-S2 peaks too early in August-September. Additionally, many individual models (including those models that accurately reproduce the observed seasonality of ENSO) have amplitudes that are too strong or too weak compared to the observed variability, which may affect the strength of the simulated teleconnections (white text, Fig. 1). However, previous studies have shown that long time periods (in the order of centuries) may be required to adequately sample ENSO's amplitude (e.g. Wittenberg 2009; Stevenson et al. 2010), and as such, we select models based on the seasonality criteria alone. The subset of 28 CMIP5 models shown to accurately simulate the seasonality of ENSO variability are retained for the following analyses.

\section{ENSO teleconnections in the CMIP5 models and MPI-GE}

\subsection{Global teleconnection patterns in ENSO composites}

ENSO variability within the models and observations is identified through an Empirical Orthogonal Function (EOF) analysis of the tropical ocean SST $\left(30^{\circ} \mathrm{N}-30^{\circ} \mathrm{S}\right.$ and $0-360^{\circ} \mathrm{E}$ ) during DJF. Separate EOFs are calculated for each model and for the historical and future time periods. The first EOF represents the spatial pattern of ENSO variability in the tropical ocean, while the associated principal component (PC1) illustrates the time evolution of ENSO variability (e.g. Power et al. 2013). The PC1 is normalised by its standard deviation and subsequently used to generate El Niño and La Niña composites for each model. El Niño years are identified 
where the normalised DJF PC1 amplitude exceeds +0.75 , while La Niña years are identified when the normalised DJF PC1 amplitude is less than -0.75 . Composites of DJF temperature and precipitation anomalies corresponding to $\mathrm{El}$ Niño and La Niña years are then calculated. The number of El Niño and La Niña events identified in the historical and future periods for each CMIP5 model are listed in Supplementary Table 1 . Note that we do not further classify the El Niño and La Niña events into central Pacific (modoki) and eastern Pacific (canonical) types (e.g. Ashok et al. 2007; Taschetto and England 2009; Yeh et al. 2018). This decision was made in order to maximise the number of ENSO events that are included in the 50-year periods.

The spatial patterns of the observed and simulated ENSO composites for the historical period (1950-1999) for temperature and precipitation are shown in Figs. 2 and 3, respectively. The significance of the composited temperature and precipitation anomalies are calculated through random sampling. 1000 random DJF composites are generated for each model and time period, with the sample size corresponding to the number of ENSO events identified. ENSO composite anomalies that are outside of the 5th and 95th percentiles of the random composites are considered significant ( $p<0.05$; see Von Storch and Zwiers 2003). This is the only criteria used to assess observational significance, indicated as stippling in Figs. 2a, b and 3a, b. For the CMIP5 multi-model mean (MMM) and MPI-GE multi-ensemble mean (MEM) composites an additional consistency test is applied. Stippling shows areas of robust intra-model or intra-ensemble agreement on the location of the significant
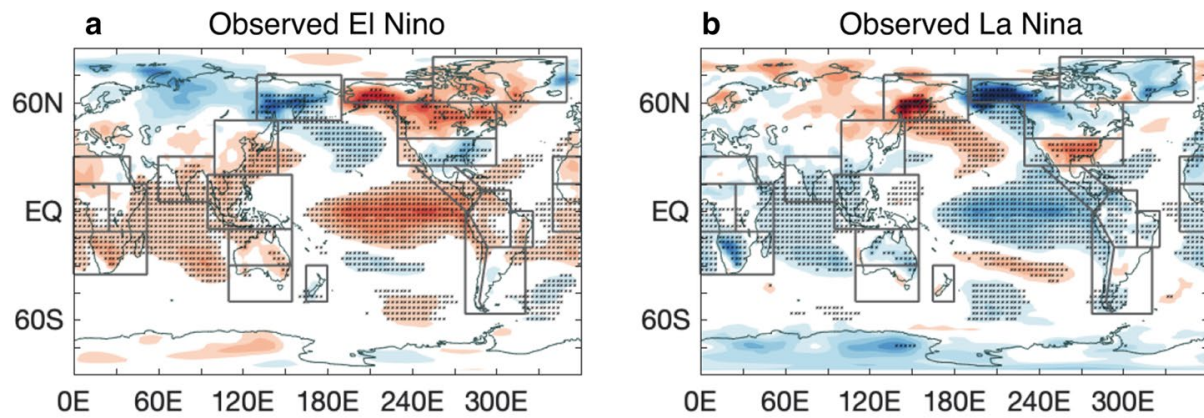

c Historical CMIP5 MMM El Nino
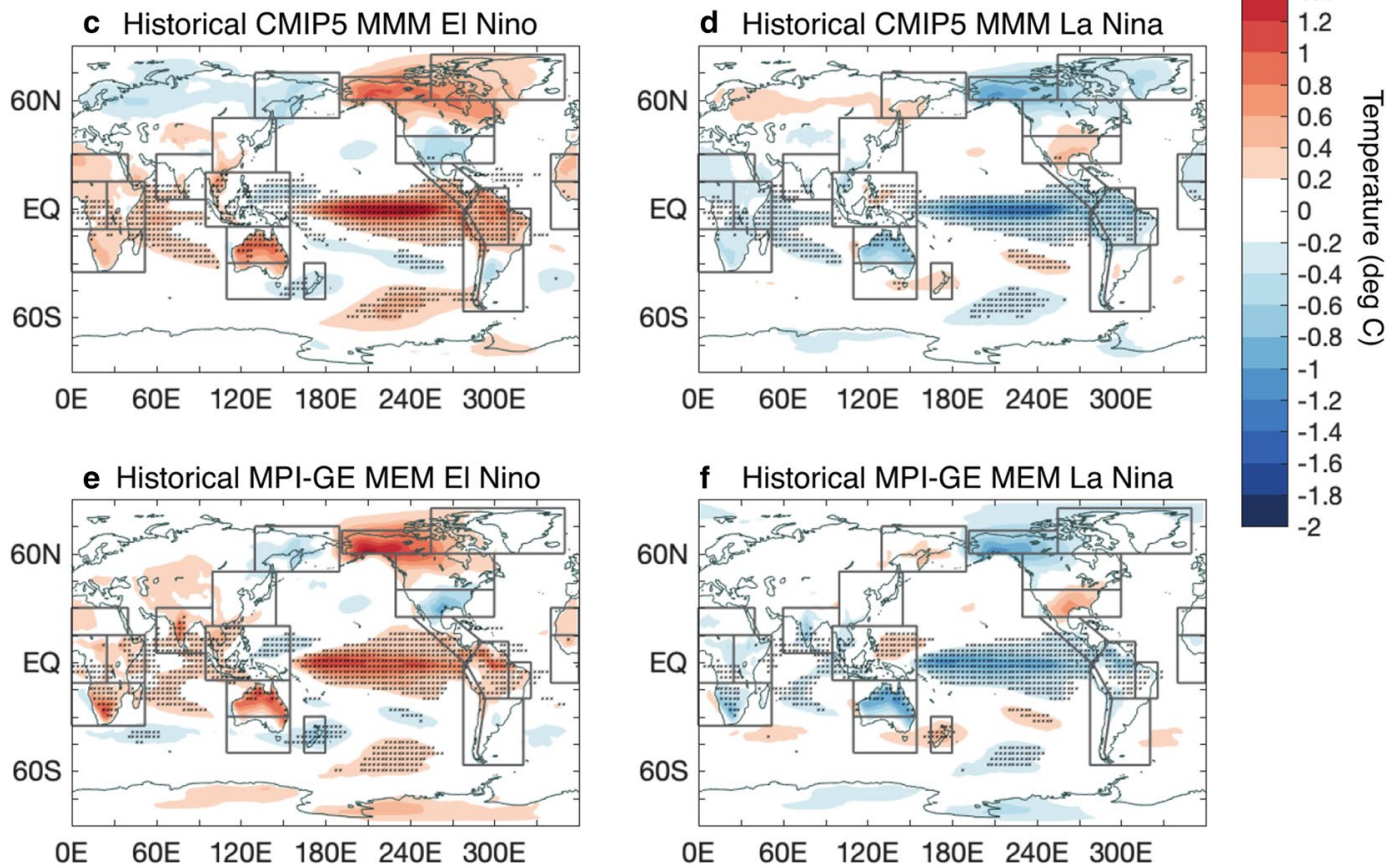

Fig. 2 Historical period observed (a, b), CMIP5 MMM (c, d) and MPI-GE MEM (e, f) DJF temperature composites for El Niño and La Niña, respectively. Observed temperature composites are NCEP/ NCAR reanalysis between 1953 and 2002. Stippling in $\mathbf{a}$ and $\mathbf{b}$ indicates significant teleconnections at $p<0.05$. For the CMIP5 MMM (1950-1999; c, d) stippling shows where at least 18/28 models agree

on the location of significant teleconnections, equivalent to $p<0.10$. For the MPI-GE MEM (1950-1999; e, f) stippling shows where at least $57 / 100$ ensemble members agree on the location of significant teleconnections, equivalent to $p<0.10$. Grey boxes in all panels indicate region boundaries 

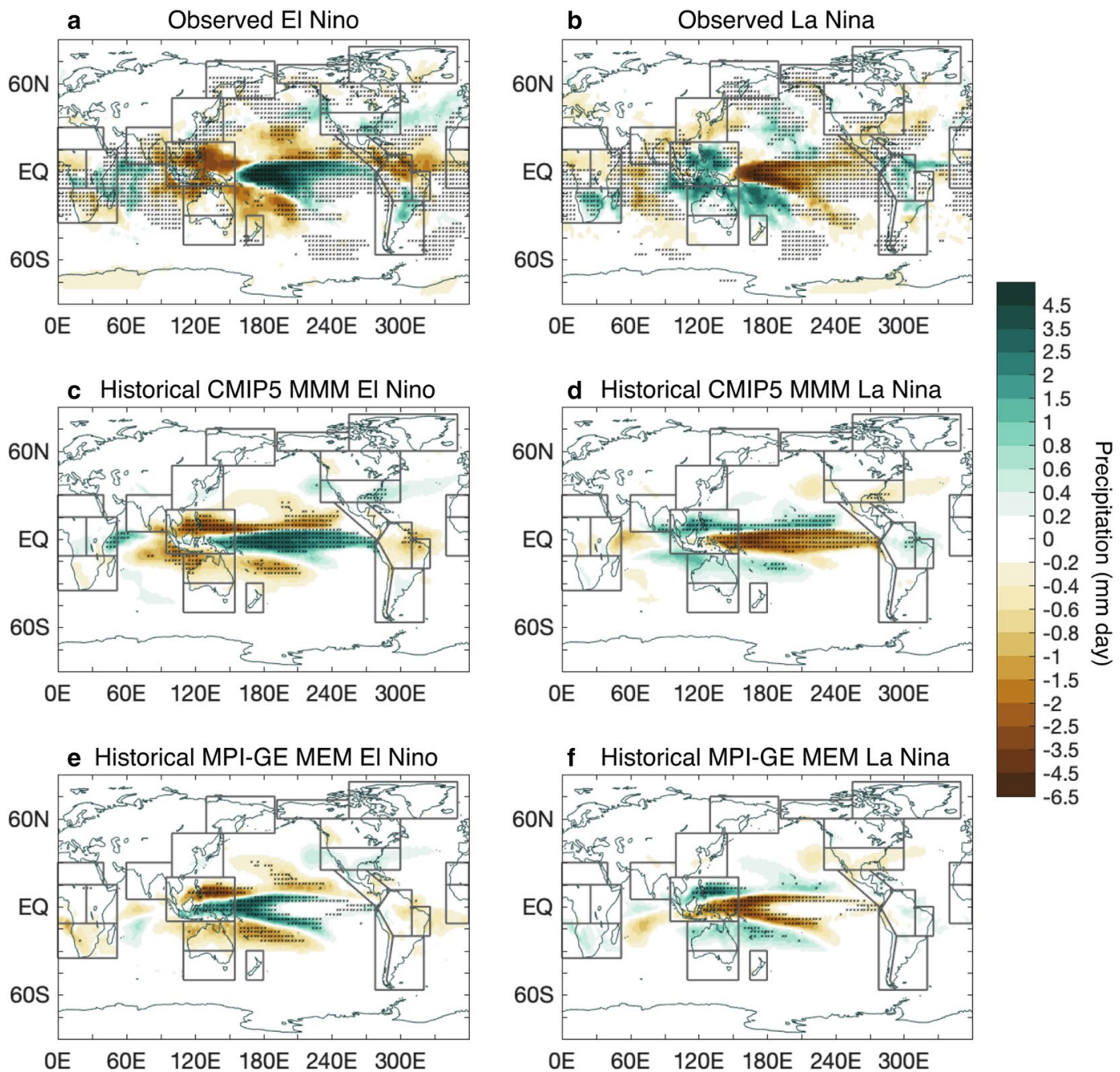

Fig. 3 Historical period observed (a, b), CMIP5 MMM (c, d) and MPI-GE MEM $(\mathbf{e}, \mathbf{f})$ DJF precipitation composites for El Niño and La Niña, respectively. Observed precipitation composites are CMAP data between 1984 and 2010. Stippling in a and b indicates significant teleconnections at $p<0.05$. For the CMIP5 MMM (1950-1999; c, d) stippling shows where at least 18/28 models agree on the loca-

tion of significant teleconnections, equivalent to $p<0.10$. For the MPI-GE MEM (1950-1999; e, f) stippling shows where at least $57 / 100$ ensemble members agree on the location of significant teleconnections, equivalent to $p<0.10$. Grey boxes in all panels indicate region boundaries

teleconnections (identified separately in each model using the random sampling method described above; Figs. 2 and 3 ). At each grid point, the threshold for significant intermodel agreement is 18 or more of the 28 CMIP5 models, and 57 or more of the 100 MPI-GE ensemble members, displaying a significant teleconnection. This level of intermodel agreement is equivalent to the $90 \%$ significance level based on a binomial distribution (e.g. Power et al. 2012).

The CMIP5 MMM simulates the majority of the observed ENSO teleconnections, particularly in the tropics (Figs. 2 and 3), consistent with previously reported findings (e.g. Weare 2013; Dai and Arkin 2017; Langenbrunner and Neelin 2013). The spatial correlation between the observed and CMIP5 MMM temperature composites for land areas (within $75^{\circ} \mathrm{N}-75^{\circ} \mathrm{S}$ ) is 0.71 for El Niño and 0.68 for La Niña. The

correlations are lower for precipitation; 0.44 for El Niño and 0.48 for La Niña. The MPI-GE MEM shows similarity to the observations that is comparable to that of the CMIP5 MMM, with a spatial correlation of 0.64 during El Niño and 0.66 during La Niña for temperature, and 0.29 and 0.42 for precipitation, respectively.

In the tropics, there is strong model agreement with respect to the patterns of the observed ENSO teleconnections for both ensembles. For example, evident in Fig. 2, both the CMIP5 MMM and MPI-GE MEM show robust intra-ensemble agreement on significant warmer (cooler) DJF temperatures over the Maritime Continent, northern Australia, India, Africa and equatorial South America during El Niño (La Niña). The CMIP5 MMM also shows consistent reductions (increases) in DJF precipitation over the 
Maritime Continent and northern South America during El Niño (La Niña), although the ensemble mean patterns are weaker in magnitude than the observed (Fig. 3). In the mid-to-high latitudes, features of the observed teleconnections are evident in the CMIP5 MMM and MPI-GE MEM, but the ensembles do not show significant agreement on the location of these teleconnections. This is due in part to intrinsic variability across individual models or ensemble members, which is greater in the mid-latitudes (e.g. Weare 2013; Polade et al. 2013; Joseph and Nigam 2006), as well as dynamical differences between the models (e.g. Dieppois et al. 2015; Hu et al. 2014).

In the following sections we utilise the MPI-GE, in addition to the CMIP5 ensemble, to assess to what extent the ensemble agreement on ENSO's teleconnections improves when assessed at the regional-scale, as opposed to the grid-point level shown above. The large number of ensemble members in the MPI-GE allows us to confidently isolate the ENSO signal from internal variability, as well as identify any changes that may occur according to this model. We acknowledge that the MPI-GE, as with many coupled models, has biases that limit the simulation of ENSO which affect the representation of teleconnections, including for example, simulating ENSO SSTAs in the tropical Pacific that extend too far west (evident in Fig. 2e, f; see Maher et al. 2018; Jungclaus et al. 2013; Giorgetta et al. 2013).

\subsection{Defining regional ENSO teleconnections}

Analysis regions are selected based on the presence of significant teleconnections in the observations, and thus include the majority of land in the tropics and much of the land area surrounding the Pacific Ocean (Fig. 2; see Sect. 3.1). Following PD18, we largely base our regional boundaries on those defined by the IPCC (see Supplementary Table 2; Intergovernmental Panel on Climate change (IPCC) 2012). Here however, several regional boundaries are repositioned such that ENSO teleconnections of the same sign are encompassed in one region in order to maximise the climate signal (grey boxes, Figs. 2 and 3), and subsequently our regions differ from PD18. For example, North America is divided into North- and Southern-North America to distinguish areas with positive and negative temperature teleconnections, rather than separated into East-, Central- and West-North America (as designated by the IPCC). Although geographically relevant, the IPCC definition of the North American boxes would lead to regional signal cancellation. Coordinates for the 20 region boundaries are provided in Supplementary Table 2. Note that although some of the region boundaries overlap oceans, only land grid-points are analysed.

\subsection{Effects of internal variability at the grid-point vs. regional scale}

As discussed in Sect. 3.1, there is limited intra-model and intra-ensemble agreement on the location of ENSO teleconnections at the grid-point level. Here, we assess how much internal variability may contribute to the limited agreement at the grid-point level. Utilising the large ensemble members, we calculate the spatial correlation for land areas (within $75^{\circ} \mathrm{N}-75^{\circ} \mathrm{S}$ ) between the ENSO composites for the individual members of the MPI-GE in the historical period. The median correlation for temperature is 0.47 (interquartile range (IQR) of 0.35-0.57) for El Niño and 0.40 (IQR 0.27-0.52) for La Niña. Given this is for a single model ensemble with the same forcing, the large range indicates that there is considerable diversity in the ENSO teleconnection patterns that stems from internal variability alone. This has further implications for the observed composites, which are assumed to be representative of the full range of ENSO variability (see also Deser et al. 2017). For precipitation, the median correlation is higher, at 0.60 (IQR 0.52-0.67) for El Niño, and 0.59 (IQR 0.51-0.67) during La Niña. However, this is likely a reflection of the limited precipitation anomalies outside of the tropics, evident in Fig. 3c, d.

We next determine whether using regional averages are effective in reducing internal variability and thus increasing the signal-to-noise ratio. We compare the simulated ENSO teleconnections with the observations at (1) the grid-point level, comparing all land grid-points within the 20 regions identified in Sect. 3.2; and (2) the regional-level, comparing the area-averaged composites for the 20 regions. The correlation between the individual MPI-GE simulated temperature teleconnections during El Niño and observations is higher for the regional averages, with a median correlation of 0.73 (IQR 0.58-0.80), compared to 0.51 (IQR 0.41-0.60) at the grid-point level (Fig. 4a). The standard deviation and root mean squared error (RMSE) are also typically reduced for the regional averages (Fig. 4a). The regional averages similarly improve the La Niña signal for both temperature and precipitation in the MPI-GE (Fig. 4b, d). However, there is little improvement for the El Niño precipitation teleconnection (Fig. 4c), which shows poor skill both at the gridpoint and regional scales (Fig. 4c).

The CMIP5 ensemble also shows an increased similarity with the observed ENSO teleconnections for the regional averages compared to the grid-point scale. For example, the El Niño temperature teleconnection for the CMIP5 ensemble has a median correlation of 0.69 (IQR $0.42-0.79$ ) for the regional-averages, compared to 0.46 (IQR $0.33-0.55$ ) at the grid-point level (Fig. 5a). Similarly, the standard deviation and RMSE are both reduced for the regional averages, and this increased skill is evident for both temperature and precipitation for both phases in the CMIP5 ensemble (Fig. 5). 

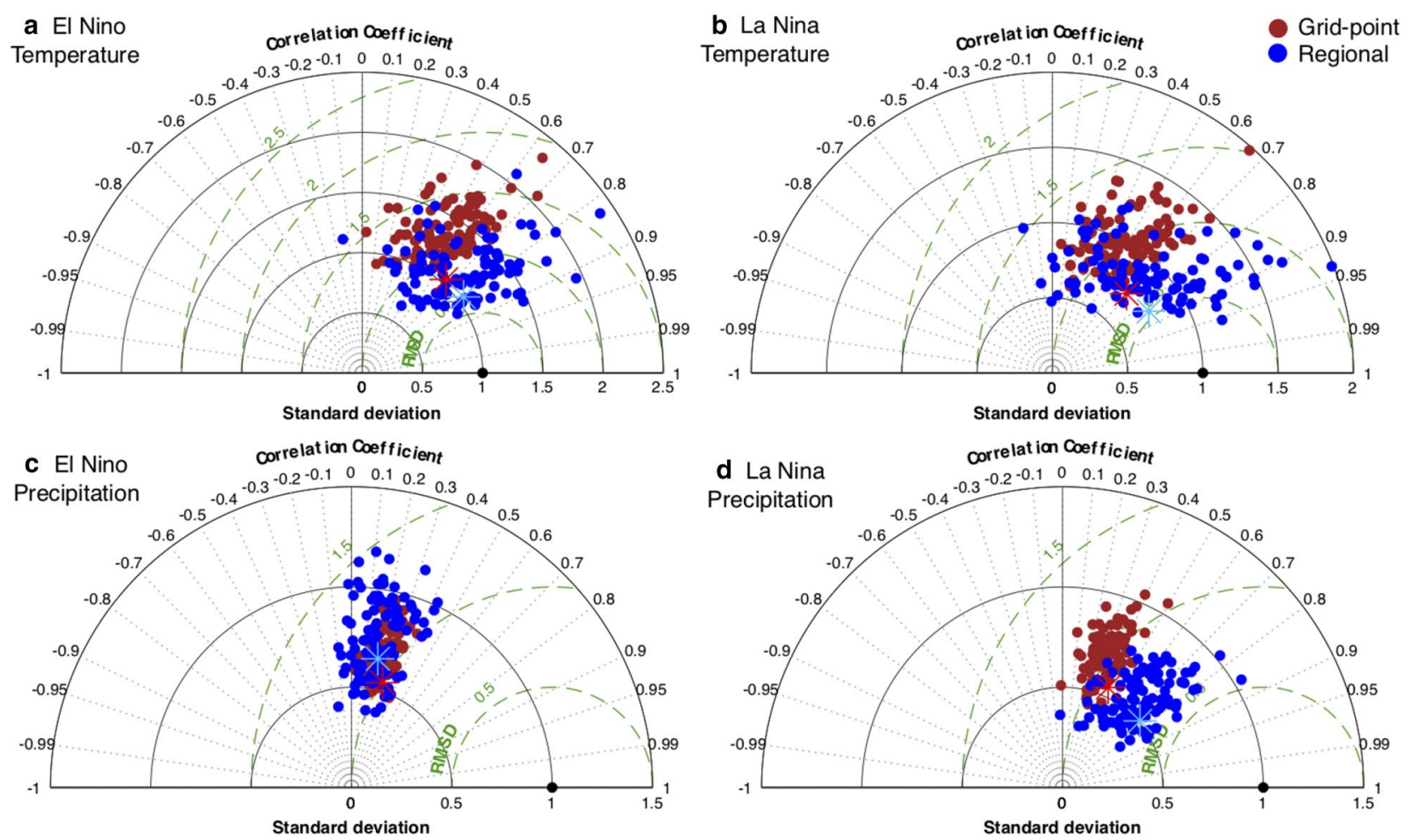

Fig. 4 Taylor diagram comparing the MPI-GE simulated teleconnections during El Niño $(\mathbf{a}, \mathbf{c})$ and La Niña $(\mathbf{b}, \mathbf{d})$ with the observed teleconnections at the grid-point (red) and regional-average (blue) level for the historical period (1950-1999). The grid-point level includes all land points within the 20 regions shown in Fig. 3, defined in Sup-

The improved similarity with the observed teleconnections at the regional-scale suggests that using regional averages may provide more reliable results that damp the influence of internal variability. The intra-ensemble variability in the MPI-GE that is evident even for the regional-averages indicates that internal variability is still an important consideration that we will attempt to quantify.

\subsection{Robust regional teleconnections in the observations and model ensembles}

Prior to identifying if there are projected changes in the regional teleconnections, we first identify the regions that show robust historical-period teleconnections at the 95\% level for the observations and models. To this end, we repeat the random sampling method described in Sect. 3.1 for the area-averaged temperature and precipitation anomalies for each region. Of the 20 regions identified, the observed regional average temperature teleconnection is significant for 13 regions during both ENSO phases, and 13 (8) regions for precipitation during El Niño (La Niña). These regions are included in Fig. 6. A binomial test is used to determine if the intra-model and intra-ensemble agreement is significant. In Fig. 6, black and magenta asterisks indicate

plementary Table 2 . The regional level is the regional average of the land points for each of the 20 regions. The observations are shown in black. The standard deviation and RMSE are normalised. Each dot represents an individual MPI-GE ensemble member and the ensemble mean is shown by the red and blue asterisks

the regions which show a significant teleconnection in the CMIP5 ensemble and MPI-GE, respectively. This includes the majority of the regions that have a significant observed teleconnection for temperature, but fewer than half of the observed regions for precipitation (Fig. 6).

We next quantify how well the models simulate the observed regional teleconnections. To this end, we compare the sign and magnitude of the simulated regional average teleconnections with those of the observations for the regions that have a significant observed teleconnection. Figure 6 shows that most models capture the sign of the observed regional teleconnections for the majority of regions. Indeed, the CMIP5 MMM (black circles) and MPIGE MEM (magenta circles) correctly simulates the sign of the observed regional average temperature teleconnections (cyan lines) for $100 \%$ of regions during El Niño and La Niña (Fig. 6a, b). Similarly, the CMIP5 MMM correctly simulates the sign of the observed precipitation teleconnection for all regions during La Niña, and $85 \%$ of regions during $\mathrm{El}$ Niño, while the MPI-GE MEM correctly simulates the sign of precipitation teleconnections for $62 \%$ of regions during El Niño and 75\% during La Niña (Fig. 6c, d). The percentage of regions that have the same sign as the observations for the individual models is listed in Supplementary Table 3. 

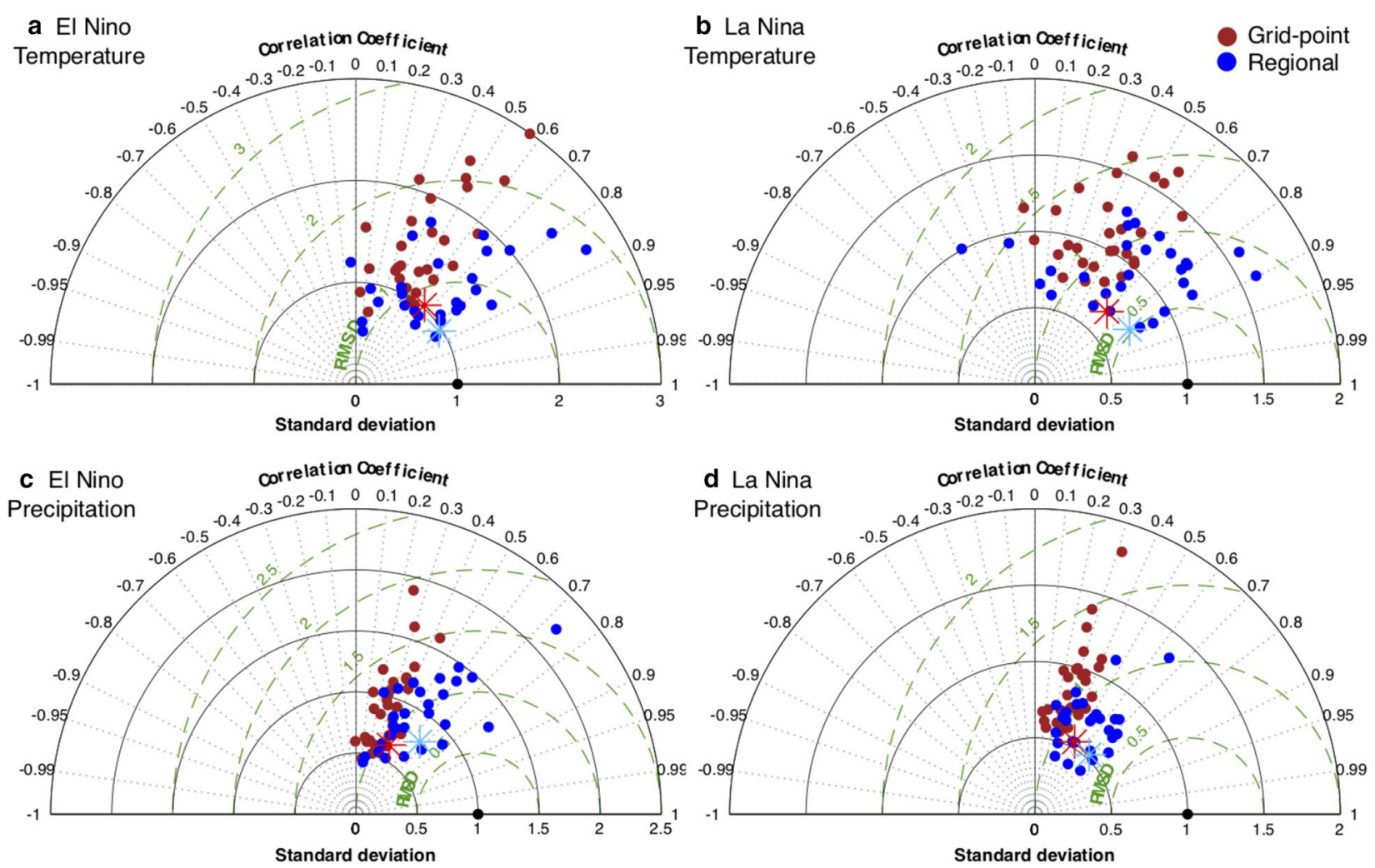

Fig. 5 Taylor diagram comparing the CMIP5 ensemble simulated teleconnections during El Niño (a, c) and La Niña (b, d) with the observed teleconnections at the grid-point (red) and regional-average (blue) level for the historical period (1950-1999). The grid-point level includes all land points within the 20 regions shown in Fig. 3,

Although the majority of models agree on the sign of the teleconnections, the magnitude of the regions teleconnections can differ markedly across models for both temperature and precipitation, indicated by the range of the ensemble members in Fig. 6. This is further evidenced by calculating the normalised RMSE between the observed and simulated regional averages, listed in Supplementary Table 3. For example, the CMIP5 models show normalised RMSEs nearly as large as the observed standard deviation for the regional average teleconnections. This is particularly evident for the temperature teleconnections during El Niño, where the models have a normalised RMSE of 0.97 on average (Supplementary Table 3). Both the CMIP5 MMM and MPIGE MEM have lower normalised RMSEs, indicating that the mean better reflects the observed teleconnection magnitude (Supplementary Table 3; Fig. 6). However, the multi-model and ensemble means typically underestimate the magnitude of the observed regional averages for precipitation (Supplementary Table 3; Fig. 6c, d).

Thus far we have shown that regional averages enhance the signal-to-noise ratio of ENSO teleconnections, improving the intra-ensemble agreement on significant ENSO defined in Supplementary Table 2. The regional level is the regional average of the land points for each of the 20 regions. The observations are shown in black. The standard deviation and RMSE are normalised. Each dot represents an individual CMIP5 model and the ensemble mean is shown by the red and blue asterisks

teleconnections. In addition, we have shown that the models correctly simulate the sign of the observed regional teleconnections for the majority of regions. Despite this, there is considerable spread evident in the magnitude of the simulated regional teleconnections, particularly for precipitation.

\section{Projected changes in regional ENSO teleconnections}

\subsection{Projected changes in the CMIP5 ensemble}

We next assess the projected changes in the strength of the regional teleconnections in the CMIP5 MMM. We focus on the regions that display robust ENSO teleconnections for both the observations and CMIP5 ensemble in the historical period (black asterisks, Fig. 6). Shown in Fig. 7, we plot the change in the regional average teleconnection for each model relative to the historical period ensemble mean (i.e. future-historical/historical MMM). Thus positive (negative) changes indicate an amplification (damping) of the historical teleconnection. Additionally, the average for the regions 

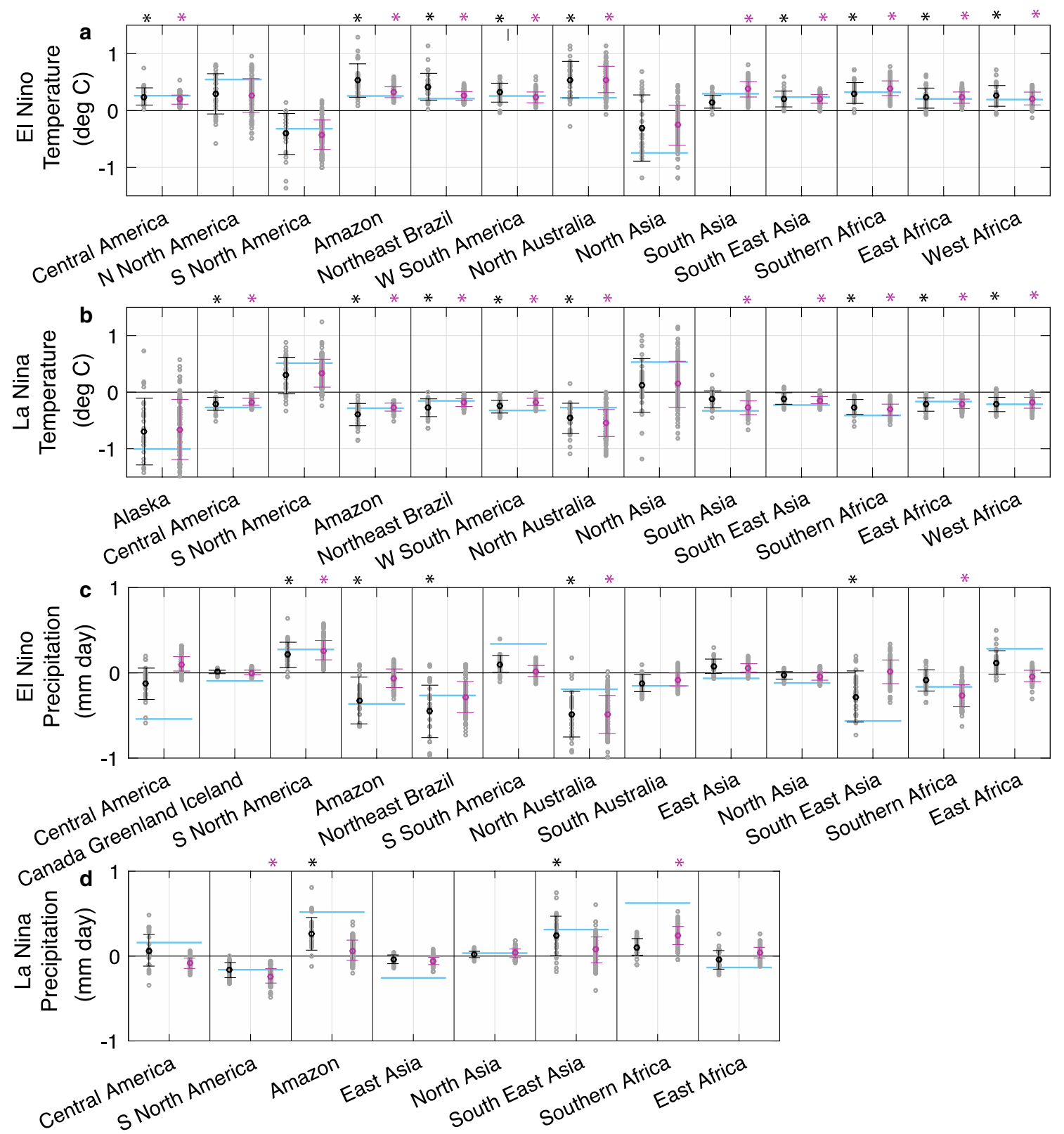

Fig. 6 Comparison of the modelled and observed regional average composites for the regions which show significant observed teleconnections during DJF in the historical period (1950-1999) during El Niño $(\mathbf{a}, \mathbf{c})$ and La Niña $(\mathbf{b}, \mathbf{d})$. The cyan line shows the magnitude of the observed regional average composite. The black circle indicates the CMIP5 MMM, with error bars indicating \pm 1 standard deviation. The magenta circle indicates the MPI-GE MEM, with error bars indicating \pm 1 standard deviation. The ensemble ranges for the CMIP5

combined is shown in the 'all region' panels. The projected change in ${ }^{\circ} \mathrm{C}$ and $\mathrm{mm} /$ day is shown in Supplementary Figure 1 . We use three significance tests to determine if there is a robust change in the teleconnection for each region: (1) the binomial test to determine if a significant number of models agree on the sign of the change (18/28 models, equivalent to $90 \%$ significance level; blue asterisks); (2) a and MPIGE are shown by the grey circles, with each circle indicating an individual model or ensemble member. Black and magenta stars indicate regions which have a robust teleconnection in the CMIP5 and MPI-GE ensembles according to the binomial distribution, respectively. This indicates the agreement of 18 or more of the 28 CMIP5 models, and 57 or more of the 100 MPI-GE ensemble members, on a significant regional teleconnection equivalent to the $90 \%$ significance level

$t$ test to determine if the magnitude of the ensemble mean change is significant ( $p<0.05$; red asterisk); and (3) the 5th and 95th percentile range (cyan lines) indicating if the projected change is greater than what could be expected due to internal variability, further detailed below.

To estimate how much internal variability within the CMIP5 ensemble may contribute to the projected changes 


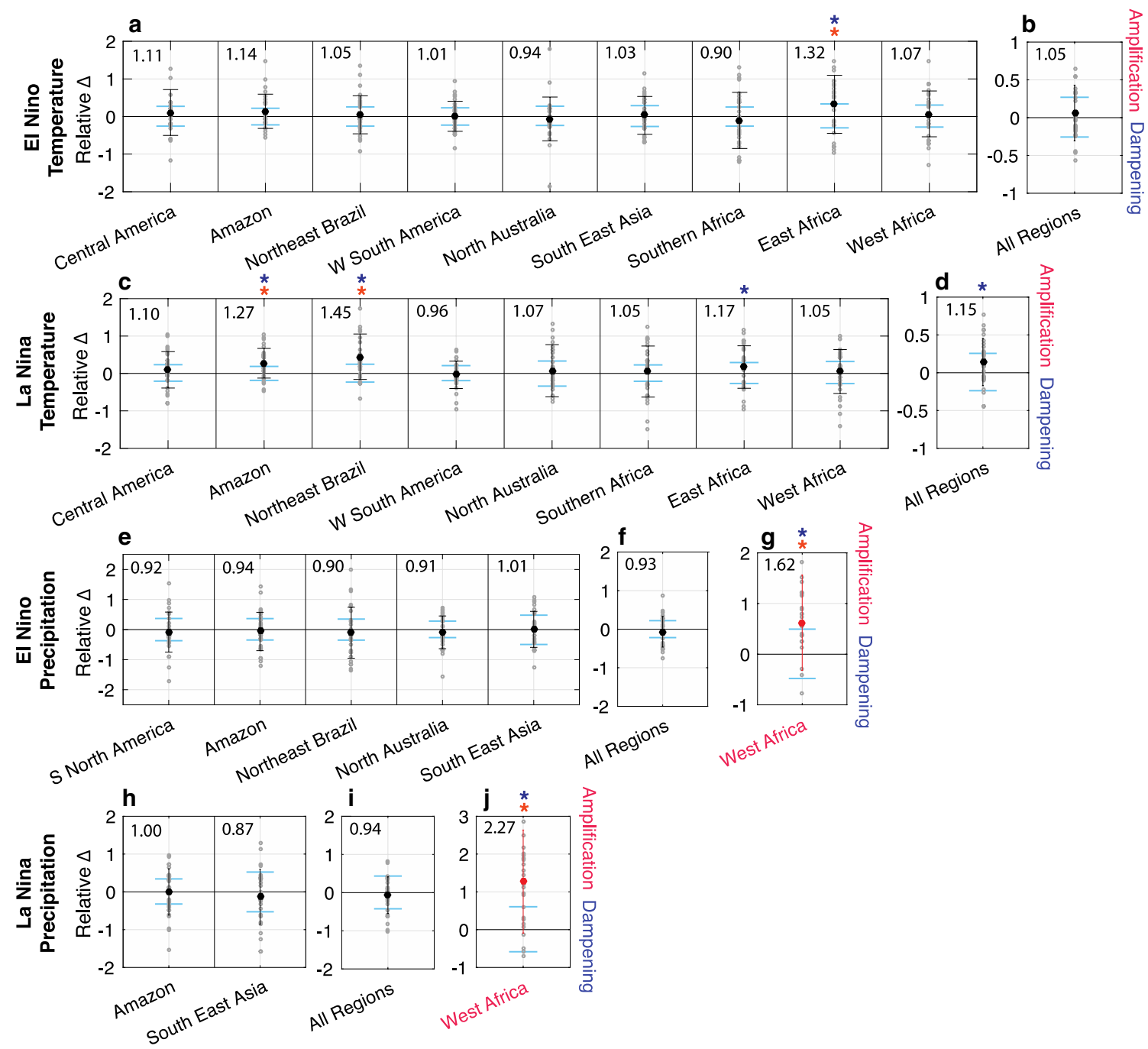

Fig. 7 Projected change in the strength of the CMIP5 MMM regional average El Niño and La Niña composites during DJF in the future period (2040-2089), relative to the historical period (1950-1999). Black circles show the CMIP5 MMM, \pm 1 standard deviation and range (as in Fig. 4). Cyan lines indicate the 5th and 95th percentiles of internal variability calculated from the CMIP5 pre-industrial control composites. Two additional significance tests are used: (1) blue

in regional teleconnection strength we use the pre-industrial control simulations. Following the method described in Sect. 3.1, we calculate ENSO composites separately for each 50-year period from the pre-industrial control simulations for each model. We then calculate two "ensembles" of 28 (the number of CMIP5 models used) randomly selected ENSO composites from the pre-industrial control ensemble, and compare the difference in the mean regional average teleconnection strength. We repeat this random sampling 1000 times, and calculate the 5th and 95th percentiles from the 1000 samples. The percentiles are shown relative to the historical period for each region (Fig. 7, cyan lines). Regions for which the mean change is outside of the confidence asterisks indicate that there is significant agreement on the sign of change (binomial test; 18/28 models agree) and (2) red asterisks indicate the ensemble mean is significantly different using a $t$ test. The 'All regions' panels $(\mathbf{b}, \mathbf{d}, \mathbf{f}, \mathbf{i})$ indicate the average relative change in teleconnection strength for all regions included in $(\mathbf{a}, \mathbf{c}, \mathbf{e}, \mathbf{h})$. Projected change in West Africa shown in red $(\mathbf{g}, \mathbf{j})$

intervals are thus unlikely to be due to internal variability alone.

Figure 7a shows a projected strengthening of the MMM regional average temperature teleconnection during El Niño for 7 out of the 9 regions (c.f. Supplementary Figure 1). This increase is reflected in the all-region average, which shows that the models simulate slightly stronger El Niño impacts in the future period on average (Fig. 7b). Despite this, only one individual region (East Africa) shows a significant increase based on both the $t$ test and binomial test (blue and red asterisks, Fig. 7a). Here, the MMM regional average temperature teleconnection is projected to be 1.3 times the magnitude of the historical teleconnection in the future period. However, 
the projected change is within the 5th and 95th percentiles, suggesting the change could be due to internal variability.

The MMM temperature teleconnection during La Niña is similarly projected to strengthen in the future simulations for 7 out of the 8 regions (Fig. 7c). However, robust changes are only evident over the Amazon and northeast Brazil regions in equatorial South America. The MMM future anomalies for these regions are 1.3 and 1.4 times that of the historical period, respectively. Additionally, the MMM shows a significant strengthening of the La Niña teleconnection when averaged across all regions, with 18/28 models agreeing on the amplification (blue star, Fig. 7d). Furthermore, the level of agreement on a projected amplification (i.e. projected for 7 out of 8 regions) is significant $(p<0.05)$ based on binomial distribution. This is consistent with previous studies that have suggested large-scale, multiple region, agreement on an enhanced teleconnection may imply a significant change in the ENSO signal, but one that may not be significant at the regional scale due to internal climate variability (e.g. Camberlin et al. 2004; Power and Delage 2018). Note this is only significant here for the La Niña temperature teleconnection.

Figure $7 \mathrm{e}$, h show that the models do not project robust changes in the regional precipitation teleconnections for any of the regions which have significant teleconnections in the historical period. For the majority (71\%) of these regions, the MMM projected precipitation teleconnections are slightly weaker in the future simulations compared to the historical period. For example, the Amazon region response is found to be slightly weaker for both El Niño and La Niña (Fig. 7e, h). Although individual models project changes in the magnitude of the regional teleconnections, indicated by the ensemble range (grey circles), the all-region average does not indicate significant changes in the magnitude of the precipitation teleconnections (Fig. 7f, i).

The spatial patterns of the ensemble mean change in the ENSO composites is shown in Fig. 8. Stippling in Fig. 8 indicates that the ensemble mean composites are significantly different $(p<0.05)$ between the two periods according to a $t$ test calculated at each grid point. Consistent with the regional-scale changes shown in Fig. 7, the CMIP5 MMM temperature teleconnections strengthen over East Africa during El Niño, and equatorial South America during La Niña (Fig. 8a, b). Additionally, the CMIP5 MMM shows significant changes in the precipitation teleconnection over west Africa during El Niño and La Niña (Fig. 8c, d). Although this region did not show a significant regional teleconnection in the historical period (black asterisks, Fig. 6), the regional average teleconnection is significant in the CMIP5 ensemble in the future period (calculated by repeating the random sampling method detailed in Sect. 3.2 for the future period composites). This change in teleconnection significance between the historical and future period is underpinned by a robust strengthening of the historical precipitation anomalies for west Africa during both El Niño and La Niña (shown in red, Fig. $7 \mathrm{~g}, \mathrm{j}$ ). The future teleconnection magnitudes are 1.6 and 2.3 times that of the historical period during El Niño and
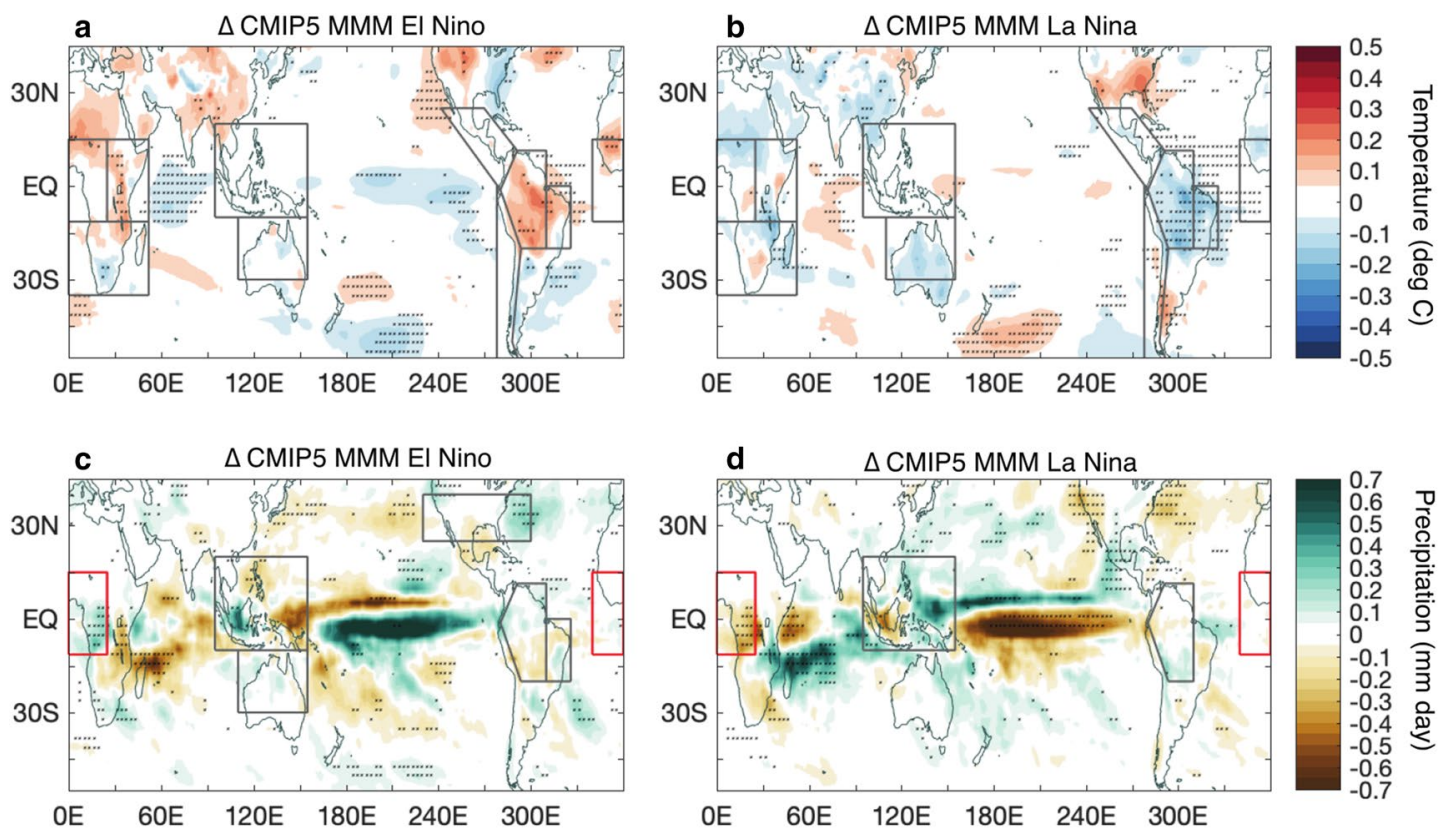

Fig. 8 Difference (2040-2089 to 1950-1999) in the DJF temperature and precipitation composites during El Niño $(\mathbf{a}, \mathbf{c})$ and La Niña $(\mathbf{b}, \mathbf{d})$ for the CMIP5 MMM. Stippling indicates the ensemble mean composite is significantly different at the grid point scale using a $t$ test $(p<0.05)$. Black outlines indicate regions shown in Fig. 7. Red outlines indicate the West Africa region which is significant in the future period only, shown in red in Fig. 7 (g, j) 
La Niña, representing on average a difference of 0.11 and $-0.13 \mathrm{~mm} /$ day, respectively (Supplementary Figure $1 \mathrm{~g}, \mathrm{j}$ ).

\subsection{Projected changes in the MPI-GE}

We next assess the projected changes in the regional teleconnections for the MPI-GE, focusing on the regions that have significant observed and simulated teleconnections in the historical period for this model (magenta asterisks, Fig. 6). As in Fig. 7, we show the change in the regional average teleconnection for each model relative to the historical period ensemble mean, identifying regions where the change is robust according to the binomial test and $t$ test (Fig. 9). Additionally, Supplementary Figure 2 shows the projected change in ${ }^{\circ} \mathrm{C}$ and $\mathrm{mm} /$ day.

The temperature teleconnections in the MPI-GE MEM are projected to strengthen and weaken for an equal number of regions (5/10) for both El Niño and La Niña (Fig. 9a, c; c.f. Supplementary Figure 2). This is reflected in the 'all region' averages, for which there is no significant change in the MEM (Fig. 9b, d). However, the projected changes during El Niño are significant according to both the binomial test and $t$ test for four individual regions. This includes a strengthening over northeast Brazil, and weakening over west South America, Southeast Asia and southern Africa. The respective future anomalies are 1.3, 0.82, 0.76, and 0.90 times the magnitude of the historical anomalies, respectively. A robust strengthening is further evident for northeast Brazil during La Niña (Fig. 9c), with future anomalies 1.2 times stronger than the historical period.

The MPI-GE MEM projects a weakening of the precipitation teleconnections during El Niño and La Niña for all regions considered, which is also evident in the 'all region' panels (Fig. 9e-h). A significant weakening is only evident during La Niña for southern Africa, with future anomalies 0.86 times the magnitude of the historical anomalies (Fig. 9g).

The spatial patterns of the MPI-GE mean change in the ENSO composites are shown in Fig. 10. The MPI-GE shows significant grid-point scale changes for many areas (Fig. 10), including for regions identified above, such as southeast Asia and South America. Additionally, we repeated the random
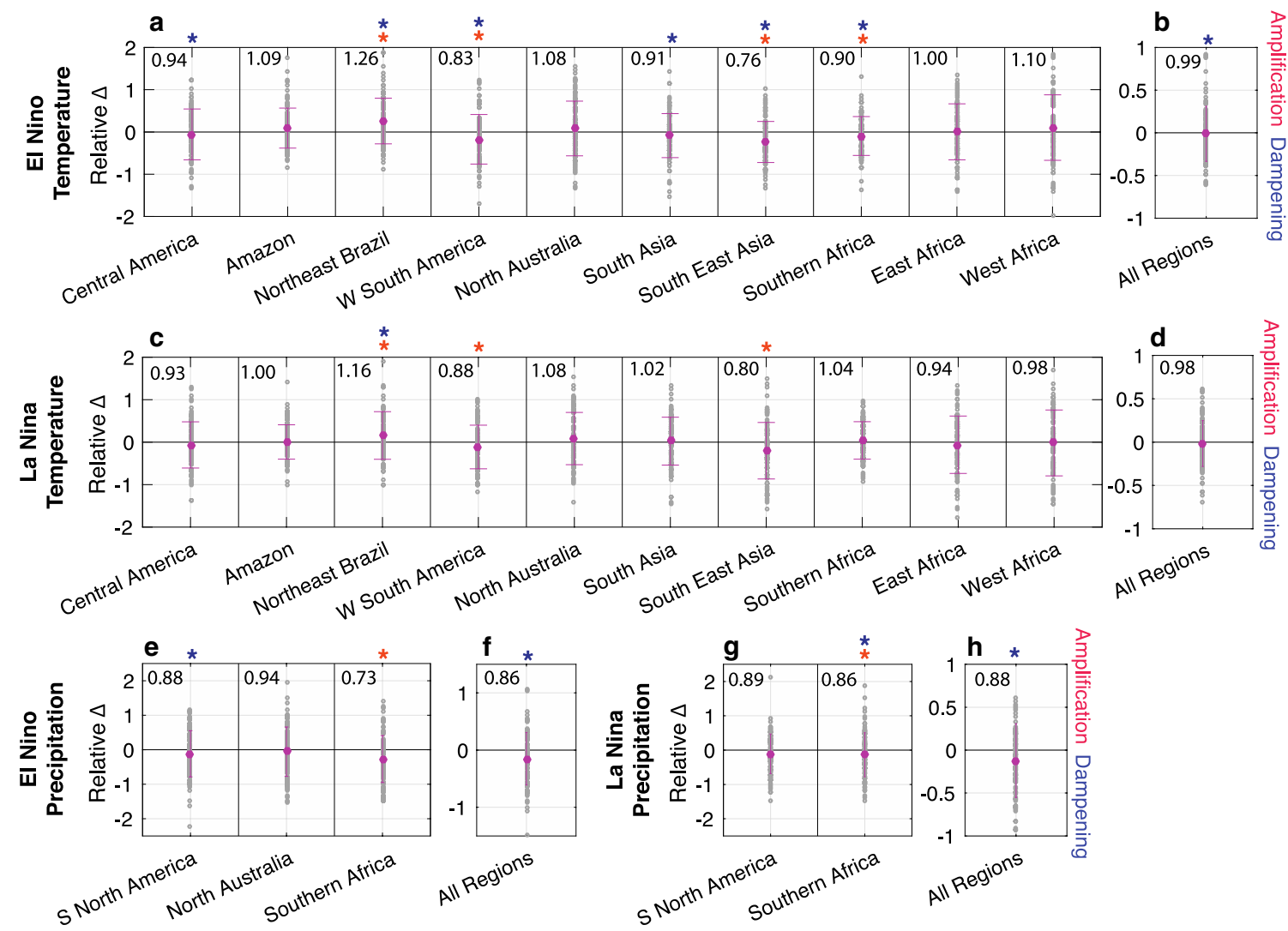

Fig. 9 Projected change in the strength of the regional average MPIGE MEM El Niño and La Niña composites during DJF in the future period (2040-2089), relative to the historical period (1950-1999). Magenta circles show the MPI-GE MEM, \pm 1 standard deviation and range. Two significance tests are used: (1) blue asterisks indicate that

there is significant agreement on the sign of change (binomial test; $57 / 100$ ensemble members) and (2) red asterisks indicate the ensemble mean is significantly different using a $t$ test. The 'All regions' panels $(\mathbf{b}, \mathbf{d}, \mathbf{f}, \mathbf{h})$ indicate the average relative change in teleconnection strength for all regions included in $\mathbf{a}, \mathbf{c}, \mathbf{e}, \mathbf{g}$ 

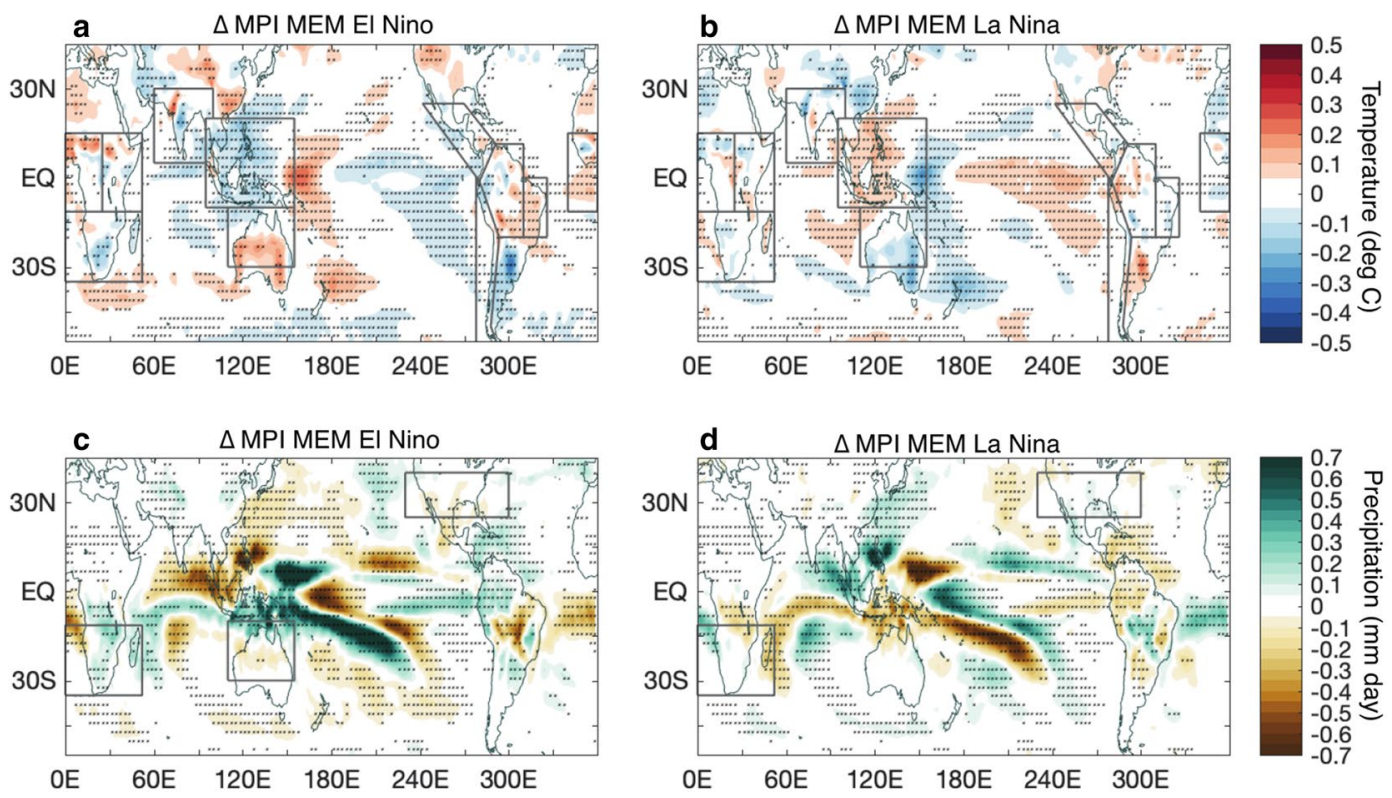

Fig. 10 Difference (2040-2089 to 1950-1999) in the DJF temperature and precipitation composites during El Niño (a, c) and La Niña (b, d) for the MPI-GE MEM. Stippling indicates the ensemble mean

sampling analysis (detailed in Sect. 3.2) for the future period composites and did not find additional regions that have significant teleconnections at the regional scale exclusively for the future period.

It should be emphasised that these projected changes are from a single model, and our CMIP5 analysis indicates strong model-dependency in the teleconnection changes. Moreover, using two other large ensemble experiments Fasullo et al. (2018) find a broad-scale strengthening of the temperature teleconnections over South America, while in contrast, the GFDL-ESM2M large ensemble shows weakening over the Amazon region. The projected mean change in the El Niño composite for the MPI-GE shows similarity to the GFDL-ESM2M large ensemble, with weakening of the temperature teleconnection evident over the Amazon (c.f. Fig. 10 with Fasullo et al. 2018, their Figures 1 and 4). However, different methodologies (Fasullo et al. 2018 show July-June regression patterns in comparison to the DJF composites presented here) may also contribute to the differences.

\section{Summary and discussion}

We have shown that the CMIP5 ensemble captures many of the observed regional scale ENSO teleconnections over land areas. Specifically, for the regions with significant observed teleconnections identified in this analysis, the CMIP5 models overall simulate the sign of the observed teleconnections composite is significantly different at the grid point scale using a $t$ test $(p<0.05)$. Black outlines indicate regions which are shown in Fig. 9

with $86 \%$ similarity on average, while the CMIP5 MMM captures the sign of the observed teleconnections with $96 \%$ similarity. Additionally, while there is considerable spread in the magnitude of the simulated teleconnections, the CMIP5 MMM better represents the observed teleconnection strength compared to the individual models. This indicates that despite known model deficiencies in the simulation of ENSO (e.g. Bellenger et al. 2014; Capotondi et al. 2015; Vijayeta and Dommenget 2017), the CMIP5 CGCMs can provide useful information about ENSO teleconnections.

Although our regional selection was largely based on the global regions outlined by the IPCC [Intergovernmental Panel on Climate change (IPCC) 2012], in order to maximise the signal of ENSO's teleconnections in the observations and CMIP5 MMM some of the regional boundaries were altered (Supplementary Table 2). We note the use of regional averages may still lead to the aliasing of ENSO signals in some individual regions where the modelled spatial patterns (both mean patterns and changes) are substantially displaced relative to the observations or ensemble mean. However, we show using both the CMIP5 ensemble and MPI-GE that there is overall greater intermodel agreement on teleconnections at the regional scale, compared to the grid point scale, due in part to reduced internal variability at the regional scale, supporting the regional approach. In contrast to PD18, we do not use all of the IPCC defined regions of the global land area. Instead, we focus on analysing the regions that have a significant ENSO signal in the observations, while also exhibiting significant intermodel agreement 
in the model ensembles in the historical period. We further include one region (West Africa) that has significant intermodel agreement on a teleconnection in the future period only. We note that ENSO may have an impact on temperature and precipitation variability for other regions, however these were not found to be significant in this analysis.

We show that there is an amplification of the simulated CMIP5 MMM regional average temperature teleconnections during DJF in most regions when comparing projected ENSO composites from the high-emission RCP8.5 simulations with those of the historical simulations. The CMIP5 MMM temperature teleconnection is projected to intensify for 7 out of 9 regions during El Niño, and 7 out of 8 regions during La Niña. For La Niña, this level of agreement of an amplification is unlikely to be caused by internal variability alone. In contrast to the CMIP5 models, however, the MPI-GE does not display a predominant amplification of the ENSO teleconnections in the future. Indeed, the majority of MPI-GE ensemble members project a slight weakening of the teleconnections when averaged over land regions.

While all the regions considered (i.e. those with significant observed and historical teleconnections) show a slight decrease in the precipitation response to both El Niño and La Niña for the CMIP5 MMM, the projected changes are not significant using either of the tests applied. This result appears to contrast with those of PD18, who show that the CMIP5 MMM projects strengthened regional precipitation teleconnections during DJF for the majority of regions included in their analysis. We note that there are differences in the methodology that may lead to these differences. For example, although similar time periods are assessed (1950-1999 and 2050-2099 in PD18, and 1950-1999 and 2040-2089 here), PD18 analyse the ensemble mean RCP8.5 simulations from 36 CMIP5 models (compared to 28 used here), and compare ENSO composites relative to the mean of each period, while here we calculate composites using 13-year high-pass filtered anomalies. Despite these methodological differences, the PD18 projected change in the DJF CMIP5 MMM El Niño precipitation teleconnection is the same sign for 4 out of the 5 regions that we present, including decreases in the teleconnection magnitude for the Amazon, north east Brazil and East Africa, and a robust amplification of the El Niño precipitation teleconnection over West Africa (c.f. Fig. 7 and Power and Delage 2018, their Figure 6). These similarities suggest that it is the inclusion of more regions in PD18 that gives rise to the increased proportion of amplified teleconnections.

For individual regions, many of the mean changes evident for the CMIP5 MMM are not significant, and thus may be a consequence of internal variability or due to the limited sample size. However, we find robust changes for some regions. For the CMIP5 MMM, this includes strengthening of the La Niña temperature teleconnection over equatorial
South America, specifically the Amazon and northeast Brazil regions. The projected changes over South America are consistent with Fasullo et al. (2018). Further, for the CMIP5 ensemble, the majority of significant regional changes occur during the La Niña phase, which may be due to model biases or suggestive of a possible asymmetry in the ENSO response to future warming. Furthermore, both the CMIP5 ensemble and MPI-GE agree on the projected strengthening in the temperature response over northeast Brazil during La Niña (c.f. Figs. 7c and 9c). The MPI-GE additionally projects a robust strengthening over northeast Brazil during El Niño, as well as weakening of the west South America and weakening of the temperature teleconnection over Southeast Asia regions during both El Niño and La Niña. For the precipitation teleconnections, robust changes are evident for only one region, southern Africa, and only for the MPI-GE, which projects a weakening of the La Niña impacts.

Although the West Africa region does not show a significant observed or MMM teleconnection for precipitation in the historical period, the region becomes significant in the future period and the models project a robust increase in the teleconnection strength for both ENSO phases. This result is consistent with the findings of PD18 and Bonfils et al. (2015). Previous studies have reported that there is considerable local variability in the large-scale controls on precipitation for west Africa in the observational record (e.g. Balas et al. 2007; Todd and Washington 2004; Dezfuli and Nicholson 2013), with additional uncertainty arising from inconsistent observations (Washington et al. 2013; Maidment et al. 2015). However, ENSO has been shown to have an influence on precipitation for the central-west Africa region during austral spring-summer (October-December), with increased (decreased) rainfall typically associated with El Niño (La Niña) events (Dezfuli and Nicholson 2013). The models suggest this teleconnection may become more important in the future (Fig. 8; see also Bonfils et al. 2015; Power and Delage 2018). Further investigation is thus required to better understand this projected change.

We note that the magnitude of the changes in ENSO teleconnections is associated with the changes in ENSO amplitude in the models, consistent with previous findings (Bonfils et al. 2015; Perry et al, 2017). For example, the regression relationship between the models change in ENSO amplitude (calculated as the 2040-2089 to 1950-1999 Niño 3.4 region SSTA standard deviation) and the relative change in the temperature teleconnection magnitude for all regions across the models has an explained variance $\left(\mathrm{R}^{2}\right)$ of 0.69 for El Niño, and 0.57 for La Niña. This suggests that on average, models with increasing ENSO amplitude show stronger temperature teleconnections, and vice versa. However, although on average the models show a reduction in the amplitude of ENSO SSTAs (Fig. 8; see also Power and Delage 2018; Stevenson et al. 2012), there is an average increase in the 
teleconnection magnitude for temperature. For example, the regression relationships between the change in SSTA amplitude and the relative change in magnitude of the temperature teleconnections for the individual models have positive intercepts of 0.10 for El Niño and 0.17 for La Niña (not shown). However, for the individual regions, the change in ENSO SST amplitude explains less of the change in teleconnection magnitude. Indeed, there is not a significant relationship between the change in magnitude and the change in ENSO variability for all of the individual regions (not shown). Therefore, although ENSO amplitude changes are a component of the change in teleconnection strength, and thus contribute to the intermodel uncertainty in the projected change, there are additional mechanisms involved (e.g. Power et al. 2013; Huang and Xie 2015).

The mechanisms that may give rise to the projected changes in ENSO's remote impacts in the coupled-models have not been addressed in this investigation. In the tropical Pacific, studies have shown that ENSO-driven convection increases and shifts eastward due to changes in the tropical mean state (e.g. Power et al. 2013; Chung et al. 2014; Huang and Xie 2015; Huang 2016). Projected changes in ENSO's teleconnections outside of the tropical Pacific have previously also been associated with these changes (e.g. Kug et al. 2010; Zhou et al. 2014; Perry et al. 2017), and as such may further explain the regional changes. In addition, changes in the global mean climate may further influence the remote teleconnections. For example, large-scale warming is projected to increase humidity and atmospheric static stability, contributing to a weakening of climatological circulation in some regions, including the Pacific Walker Circulation (e.g. Chou and Neelin 2004; Vecchi and Soden 2007; Seager et al. 2012). Such processes are relevant for ENSO teleconnections (e.g. Chiang and Sobel 2002; Su and Neelin 2003; Parhi et al. 2016), and may act to alter the ENSO teleconnections in the future period. Further investigation into the dynamics of regional teleconnections in a warmer climate, including differences in the CMIP5 ensemble, is thus required.

The question remains to what extent any changes in teleconnections will become evident over the next century. PD18 and Bonfils et al. (2015) illustrate that the projected changes in ENSO's teleconnections are small in comparison to those expected from mean climate change for the majority of regions. In addition, for many individual regions, a signal of change does not emerge from the noise associated with internal variability and structural differences between models. Thus, changes in ENSO's teleconnections may only become identifiable at large-scales (for example, the temperature teleconnections presented here, and in Power and Delage 2018), or over time periods longer than the fifty years considered here (e.g. Sterl et al. 2007). From the results presented here, however, it is evident that the magnitude of the projected changes in the majority of ENSO's regional teleconnections is small relative to its historical variability, and thus may not be distinguishable above natural variability for some time to come.

Acknowledgements We acknowledge the World Climate Research Programme's Working Group on Coupled Modelling and the climate modelling groups (listed in Fig. 1) for producing and making available CMIP5 model output, and the Max Planck Institute for Meteorology for the MPI-GE output used in this research. This research was supported by the Australian Research Council (ARC) including the ARC Centre of Excellence for Climate System Science and ARC Centre of Excellence for Climate Extremes. We thank the anonymous reviewers for their constructive feedback that has improved this research.

\section{References}

Ashok K, Behera SK, Rao SA, Weng H, Yamagata T (2007) El Niño Modoki and its possible teleconnection. J Geophys Res Ocean 112:1-27. https://doi.org/10.1029/2006JC003798

Balas N, Nicholson SE, Klotter D (2007) The relationship of rainfall variability in West Central Africa to sea-surface temperature fluctuations. Int J Climatol 27:1335-1349. https://doi.org/10.1002/ joc. 1456

Bellenger H, Guilyardi E, Leloup J, Lengaigne M, Vialard J (2014) ENSO representation in climate models: from CMIP3 to CMIP5. Clim Dyn 42:1999-2018. https://doi.org/10.1007/s0038 2-013-1783-Z

Bittner M, Schmidt H, Timmreck C, Sienz F (2016) Using a large ensemble of simulations to assess the Northern Hemisphere stratospheric dynamical response to tropical volcanic eruptions and its uncertainty. Geophys Res Lett 43:9324-9332. https://doi. org/10.1002/2016GL070587

Bonfils CJW, Santer BD, Phillips TJ, Marvel K, Ruby Leung L, Doutriaux C, Capotondi A (2015) Relative contributions of mean-state shifts and ENSO-driven variability to precipitation changes in a warming climate. J Clim 28:9997-10013. https://doi.org/10.1175/ JCLI-D-15-0341.1

Brands S (2017) Which ENSO teleconnections are robust to internal atmospheric variability? Geophys Res Lett 44:1483-1493. https ://doi.org/10.1002/2016GL071529

Cai W et al (2014) Increasing frequency of extreme El Niño events due to greenhouse warming. Nat Clim Chang 4:111-116. https://doi. org/10.1038/nclimate2 100

Cai W et al (2015a) ENSO and greenhouse warming. Nat Clim Chang 5:849-859. https://doi.org/10.1038/nclimate2743

Cai W et al (2015b) Increased frequency of extreme La Niña events under greenhouse warming. Nat Clim Chang 5:132-137. https:// doi.org/10.1038/nclimate2492

Camberlin P, Chauvin F, Douville H, Zhao Y (2004) Simulated ENSO-tropical rainfall teleconnections in present-day and under enhanced greenhouse gases conditions. Clim Dyn 23:641-657. https://doi.org/10.1007/s00382-004-0460-7

Capotondi A, Ham Y, Wittenberg A, Kug J (2015) Climate model biases and El Niño Southern Oscillation (ENSO) simulation. US Clivar Var 13:21-25

Chen C, Cane MA, Wittenberg AT, Chen D (2017) ENSO in the CMIP5 simulations: life cycles, diversity, and responses to climate change. J Clim 30:775-801. https://doi.org/10.1175/ JCLI-D-15-0901.1

Chiang JCH, Sobel AH (2002) Tropical tropospheric temperature variations caused by ENSO and their influence on the remote tropical climate. J Clim 15:2616-2631. https 
://doi.org/10.1175/1520-0442(2002)015\%3c2616:TTTVC B\%3e2.0.CO;2

Choi KY, Vecchi GA, Wittenberg AT (2015) Nonlinear zonal wind response to ENSO in the CMIP5 models: roles of the zonal and meridional shift of the ITCZ/SPCZ and the simulated climatological precipitation. J Clim 28:8556-8573. https://doi. org/10.1175/JCLI-D-15-0211.1

Chou C, Neelin JD (2004) Mechanisms of global warming impacts on regional tropical precipitation. J Clim 17:2688-2701. https ://doi.org/10.1175/1520-0442(2004)017\%3c2688:MOGWI $\mathrm{O} \% 3 \mathrm{e} 2.0 . \mathrm{CO} ; 2$

Chung CTY, Power SB, Arblaster JM, Rashid HA, Roff GL (2014) Nonlinear precipitation response to El Nino and global warming in the Indo-Pacific. Clim Dyn 42:1837-1856. https://doi. org/10.1007/s00382-013-1892-8

Collins $M$ et al (2010) The impact of global warming on the tropical Pacific Ocean and El Niño. Nat Geosci 3:391-397. https://doi. org/10.1038/ngeo868

Dai N, Arkin PA (2017) Twentieth century ENSO-related precipitation mean states in twentieth century reanalysis, reconstructed precipitation and CMIP5 models. Clim Dyn 48:3061-3083. https://doi.org/10.1016/j.tifs.2016.11.001

Deser C, Simpson IR, McKinnon KA, Phillips AS (2017) The Northern Hemisphere extratropical atmospheric circulation response to ENSO: how well do we know it and how do we evaluate models accordingly? J Clim 30:5059-5082. https://doi.org/10.1175/ JCLI-D-16-0844.1

Dezfuli AK, Nicholson SE (2013) The relationship of rainfall variability in western equatorial Africa to the tropical oceans and atmospheric circulation. part II: the boreal autumn. J Clim 26:66-84. https://doi.org/10.1175/JCLI-D-11-00686.1

Diaz HF, Hoerling MP, Eischeid JK (2001) ENSO variability, teleconnections and climate change. Int J Climatol 21:1845-1862. https://doi.org/10.1002/joc.631

Dieppois B, Rouault M, New M (2015) The impact of ENSO on Southern African rainfall in CMIP5 ocean atmosphere coupled climate models. Clim Dyn 45:2425-2442. https://doi. org/10.1007/s00382-015-2480-x

Fasullo JT, Otto-Bliesner BL, Stevenson S (2018) ENSO's changing influence on temperature, precipitation, and wildfire in a warming climate. Geophys Res Lett 45:9216-9225. https://doi. org/10.1029/2018GL079022

Gill AE (1980) Some simple solutions for heat-induced tropical circulation. Quart J R Met Soc 106:447-462

Giorgetta MA et al (2013) Climate and carbon cycle changes from 1850 to 2100 in MPI-ESM simulations for the Coupled Model Intercomparison Project phase 5. J Adv Model Earth Syst 5:572-597. https://doi.org/10.1002/jame.20038

Grimm AM (2011) Interannual climate variability in South America: impacts on seasonal precipitation, extreme events, and possible effects of climate change. Stoch Environ Res Risk Assess 25:537-554. https://doi.org/10.1007/s00477-010-0420-1

Herceg Bulić I, Branković Č, Kucharski F (2012) Winter ENSO teleconnections in a warmer climate. Clim Dyn 38:1593-1613. https://doi.org/10.1007/s00382-010-0987-8

Horel JD, Wallace JM (1981) Planetary-scale atmospheric phenomena associated with the southern oscillation. Mon Weather Rev 110:1495-1496. https://doi.org/10.1175/15200493(1982)110\%3c1495:COSAPA\%3e2.0.CO;2

Hoskins BJ, Karoly DJ (1981) The steady linear response of a spherical atmosphere to thermal and orographic forcing. J Atmos Sci 38:1179-1196. https://doi.org/10.1175/15200469(1981)038\%3c1179:TSLROA\%3e2.0.CO;2

Hu K, Huang G, Zheng XT, Xie SP, Qu X, Du Y, Liu L (2014) Interdecadal variations in ENSO influences on northwest PacificEast Asian early summertime climate simulated in CMIP5 models. J Clim 27:5982-5998. https://doi.org/10.1175/JCLID-13-00268.1

Huang P (2016) Time-varying response of ENSO-induced tropical pacific rainfall to global warming in CMIP5 models. part I: multimodel ensemble results. J Clim 29:5763-5778. https://doi. org/10.1175/JCLI-D-16-0058.1

Huang P, Xie S-P (2015) Mechanisms of change in ENSO-induced tropical Pacific rainfall variability in a warming climate. Nat Geosci 8:1-13. https://doi.org/10.1038/ngeo2571

Intergovernmental Panel on Climate change (IPCC) (2012) Managing the Risks of Extreme Events and Disasters to Advance Climate Change Adaptation. Cambridge University Press, Cambridge, $p$ 582

Joseph R, Nigam S (2006) ENSO evolution and teleconnections in IPCC's twentieth-century climate simulations: realistic representation? J Clim 19:4360-4377. https://doi.org/10.1175/JCLI3846.1

Jungclaus JH et al (2013) Characteristics of the ocean simulations in the Max Planck Institute Ocean Model (MPIOM) the ocean component of the MPI-earth system model. J Adv Model Earth Syst 5:422-446. https://doi.org/10.1002/jame.20023

Kalnay E et al (1996) The NCEP/NCAR 40-year reanalysis project. Bull Am Meteorol Soc 77:437-471. https://doi.org/10.1175/15200477(1996)077\%3c0437:TNYRP\%3e2.0.CO;2

Kim S, Son HY, Kug JS (2016) How well do climate models simulate atmospheric teleconnections over the North Pacific and East Asia associated with ENSO?. Clim Dyn 48:1-15. https://doi. org/10.1007/s00382-016-3121-8

Klein SA, Soden BJ, Lau NC (1999) Remote sea surface temperature variations during ENSO: evidence for a tropical atmospheric bridge. J Clim 12:917-932. https://doi.org/10.1175/15200442(1999)012\%3c0917:RSSTVD\%3e2.0.CO;2

Kug JS, Il An S, Ham YG, Kang IS (2010) Changes in El Niño and La Niña teleconnections over North Pacific-America in the global warming simulations. Theor Appl Climatol 100:275-282. https ://doi.org/10.1007/s00704-009-0183-0

Langenbrunner B, Neelin JD (2013) Analyzing ENSO teleconnections in CMIP models as a measure of model fidelity in simulating precipitation. J Clim 26:4431-4446. https://doi.org/10.1175/JCLID-12-00542.1

Latif M et al (2001) ENSIP: the El Nino simulation intercomparison project. Clim Dyn 18:255-276. https://doi.org/10.1007/s0038 20100174

Maher N, Matei D, Milinski S, Marotzke J (2018) ENSO change in climate projections: forced response or internal variability?. Res Lett, Geophys. https://doi.org/10.1029/2018GL079764

Maher N et al (2019) The Max Planck Institute grand ensemble: enabling the exploration of climate system variability. J Adv Model Earth Syst 11:2050-2069. https://doi.org/10.1029/2019MS001639

Maidment RI, Allan RP, Black E (2015) In precipitation over Africa. Geophys Res Lett 42:1-10. https://doi.org/10.1002/2015GL0657 65.Received

McPhaden MJ, Zebiak SE, Glantz MH (2006) ENSO as an integrating concept in earth science. Science 314:1740-1745. https://doi. org/10.1126/science. 1132588

Meehl GA, Teng H (2007) Multi-model changes in El Niño teleconnections over North America in a future warmer climate. Clim Dyn 29:779-790. https://doi.org/10.1007/s00382-007-0268-3

Oh J-H, Shin DW, Cocke SD, Baigorria GA (2014) ENSO teleconnection pattern changes over the Southeastern United States under a climate change scenario in CMIP5 models. Adv Meteorol 2014:116. https://doi.org/10.1155/2014/648197

Parhi P, Giannini A, Gentine P, Lall U (2016) Resolving contrasting regional rainfall responses to EL Niño over tropical Africa. J Clim 29:1461-1476. https://doi.org/10.1175/JCLI-D-15-0071.1

Perry SJ, McGregor S, Sen Gupta A, England MH (2017) Future changes to El Niño-Southern oscillation temperature and 
precipitation teleconnections. Geophys Res Lett 44:10608-10616. https://doi.org/10.1002/2017GL074509

Polade SD, Gershunov A, Cayan DR, Dettinger MD, Pierce DW (2013) Natural climate variability and teleconnections to precipitation over the Pacific-North American region in CMIP3 and CMIP5 models. Geophys Res Lett 40:2296-2301. https://doi.org/10.1002/ grl.50491

Power SB, Delage FPD (2018) El Niño-Southern oscillation and associated climatic conditions around the world during the latter half of the twenty-first century. J Clim 31:6189-6207. https://doi. org/10.1175/JCLI-D-18-0138.1

Power SB, Delage F, Colman R, Moise A (2012) Consensus on twentyfirst-century rainfall projections in climate models more widespread than previously thought. J Clim 25:3792-3809. https://doi. org/10.1175/JCLI-D-11-00354.1

Power S, Delage F, Chung C, Kociuba G, Keay K (2013) Robust twenty-first-century projections of El Niño and related precipitation variability. Nature 502:541-545. https://doi.org/10.1038/ nature 12580

Rodgers KB, Lin J, Frölicher TL (2015) Emergence of multiple ocean ecosystem drivers in a large ensemble suite with an Earth system model. Biogeosciences 12:3301-3320. https://doi.org/10.5194/ bg-12-3301-2015

Seager R, Naik N, Vogel L (2012) Does global warming cause intensified interannual hydroclimate variability? J Clim 25:3355-3372. https://doi.org/10.1175/JCLI-D-11-00363.1

Steinhoff DF, Monaghan AJ, Clark MP (2014) Projected impact of twenty-first century ENSO changes on rainfall over Central America and northwest South America from CMIP5 AOGCMs. Clim Dyn 44:1329-1349. https://doi.org/10.1007/s00382-014-2196-3

Sterl A, van Oldenborgh GJ, Hazeleger W, Burgers G (2007) On the robustness of ENSO teleconnections. Clim Dyn 29:469-485. https ://doi.org/10.1007/s00382-007-0251-z

Stevens B (2015) Rethinking the lower bound on aerosol radiative forcing. J Clim 28:4794-4819. https://doi.org/10.1175/JCLID-14-00656.1

Stevenson S, Fox-Kemper B, Jochum M, Rajagopalan B, Yeager SG (2010) ENSO model validation using wavelet probability analysis. J Clim 23:5540-5547. https://doi.org/10.1175/2010JCLI3609.1

Stevenson S, Fox-Kemper B, Jochum M, Neale R, Deser C, Meehl G (2012) Will there be a significant change to El Niño in the twentyfirst century? J Clim 25:2129-2145. https://doi.org/10.1175/JCLID-11-00252.1

Su H, Neelin JD (2003) The scatter in tropical average precipitation anomalies*. J Clim 16:3966-3977

Taschetto AS, England MH (2009) El Niño modoki impacts on Australian rainfall. J Clim 22:3167-3174. https://doi.org/10.1175/2008J CLI2589.1

Taschetto AS, Sen Gupta A, Jourdain NC, Santoso A, Ummenhofer CC, England MH (2014) Cold tongue and warm pool ENSO events in CMIP5: mean state and future projections. J Clim 27:2861-2885. https://doi.org/10.1175/JCLI-D-13-00437.1

Taylor KE, Stouffer RJ, Meehl GA (2012) An overview of CMIP5 and the experiment design. Bull Am Meteorol Soc 93:485-498. https ://doi.org/10.1175/BAMS-D-11-00094.1

Timmermann A et al (2018) El Niño-Southern oscillation complexity. Nature 559:535-545. https://doi.org/10.1038/s41586-018-0252-6
Todd MC, Washington R (2004) Climate variability in central equatorial Africa: influence from the Atlantic sector. Geophys Res Lett 31:1-4. https://doi.org/10.1029/2004GL020975

Trenberth KE, Kumar A, Karoly D, Ropelewski C, Branstator GW, Lau N-C (1998) Progress during TOGA in understanding and modeling global teleconnections associated with tropical sea surface temperatures. J Geophys Res Ocean 103:14291-14324. https:// doi.org/10.1029/97jc01444

Van Rensch P, Gallant AJE, Cai W, Nicholls N (2015) Evidence of local sea surface temperatures overriding the southeast Australian rainfall response to the 1997-1998 El Niño. Geophys Res Lett 42:9449-9456. https://doi.org/10.1002/2015GL066319

Vecchi GA, Soden BJ (2007) Global warming and the weakening of the tropical circulation. J Clim 20:4316-4340. https://doi. org/10.1175/JCLI4258.1

Vecchi GA, Wittenberg AT (2010) El Niño and our future climate: where do we stand? Wiley Interdiscip Rev Clim Chang 1:260 270. https://doi.org/10.1002/wcc.33

Vijayeta A, Dommenget D (2017) An evaluation of ENSO dynamics in CMIP simulations in the framework of the recharge oscillator model. Clim Dyn 51:1-19. https://doi.org/10.1007/s0038 2-017-3981-6

Von Storch H, Zwiers F (2003) Statistical analysis in climate research. Cambridge University Press, Cambridge, p 496

Washington R, James R, Pearce H, Pokam WM, Moufouma-Okia W (2013) Congo basin rainfall climatology: can we believe the climate models? Philos Trans R Soc B 368:20120296. https://doi. org/10.1098/rstb.2012.0296

Watanabe M, Kug JS, Jin FF, Collins M, Ohba M, Wittenberg AT (2012) Uncertainty in the ENSO amplitude change from the past to the future. Geophys Res Lett 39:1-7. https://doi. org/10.1029/2012GL053305

Weare BC (2013) El Niño teleconnections in CMIP5 models. Clim Dyn 41:2165-2177. https://doi.org/10.1007/s00382-012-1537-3

Wittenberg AT (2009) Are historical records sufficient to constrain ENSO simulations? Geophys Res Lett 36:1-5. https://doi. org/10.1029/2009GL038710

Xie PP, Arkin PA (1997) Global precipitation: a 17-year monthly analysis based on gauge observations, satellite estimates, and numerical model outputs. Bull Amer Meteor Soc 78:2539-2558. https://doi.org/10.1175/1520-0477(1997)078\%3c2539:GPAYM $\mathrm{A} \% 3 \mathrm{e} 2.0 . \mathrm{CO} ; 2$

Yeh SW et al (2018) ENSO atmospheric teleconnections and their response to greenhouse gas forcing. Rev Geophys 56:185-206. https://doi.org/10.1002/2017RG000568

Zhou ZQ, Xie SP, Zheng XT, Liu Q, Wang H (2014) Global warming-induced changes in El Nino teleconnections over the North Pacific and North America. J Clim 27:9050-9064. https://doi. org/10.1175/JCLI-D-14-00254.1

Publisher's Note Springer Nature remains neutral with regard to jurisdictional claims in published maps and institutional affiliations. 